Jeglineds josinuts

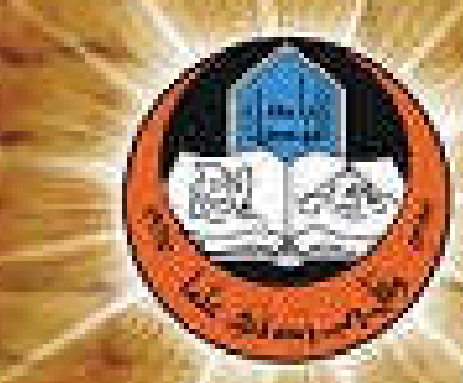

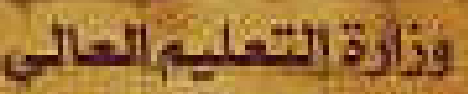

يلئيت

ISSN $2504-103 x$

$\mid \overrightarrow{8}=\square$

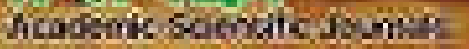

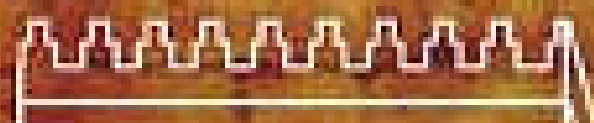

D 0,0

$y^{2}+\mathrm{H}^{2}$ 


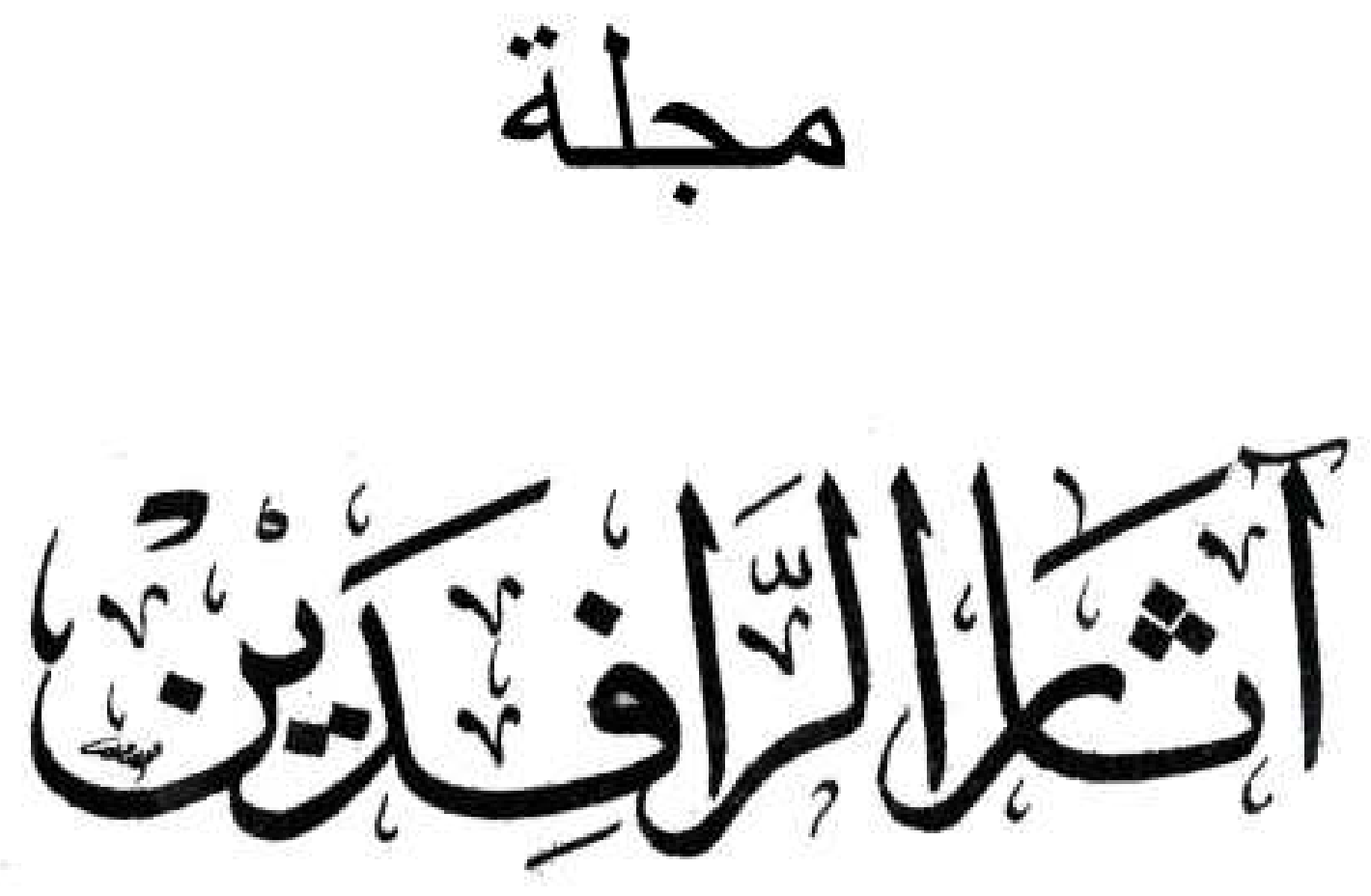

هجلة علمية هدكمة تبحث في آثار العراق و الشرق الأدنى القديم تصدر عن كلية الآثار في جامعة الموصل

E-Mail: uom.atharalrafedain@ gmail.com البريد الاكتروني

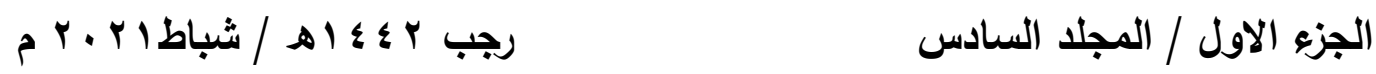

$$
\begin{aligned}
& \text { رقم الايداع في دار الكتب والوثائق بيغداد } \\
& \text { r. I السنة (IVIr) }
\end{aligned}
$$





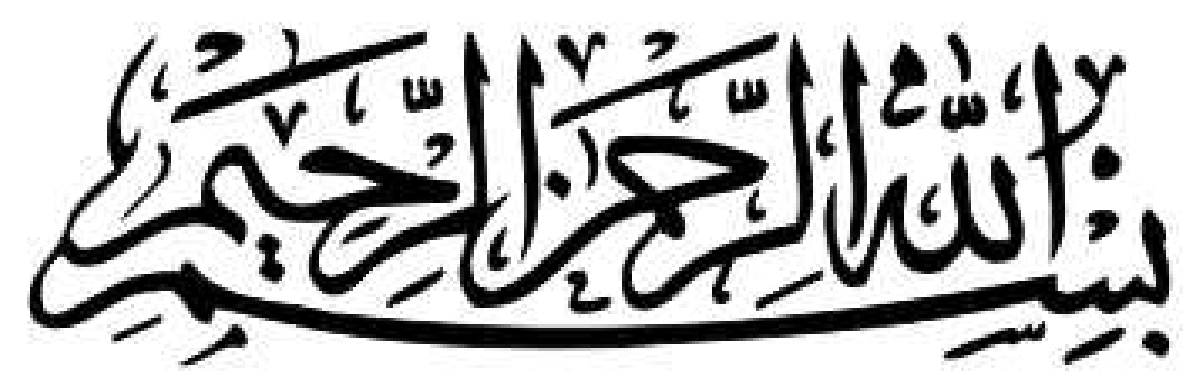





\section{هيأة التمرير}

أ. خالد سالم اسماءيل

رئيس التمرير

أ.م. هسنين حيدر عبد الواحد

الاعضاء

أ.د. اليزابيث ستون

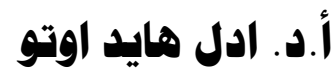

أ.د. والتز سلابيركر

أ.د. نيكولو هاركيتي

أ.د. هديب هياوي عبد الكريم

أ.د. جواد هطر الموسوي

أ.د. رفاه جاسم حمادي

أ.د. عادل هاشم علي

أ.م.د. ياسمين عبد الكريم هممد علي

أ.م.د. فيسان هوفق رشيد

أ.م.د. هاني عبد الغني عبد الله 


$$
\begin{aligned}
& \text { هقوم اللغة العربية } \\
& \text { أ.م.د. همن يميى هصمد }
\end{aligned}
$$

$$
\begin{aligned}
& \text { هقوم اللغة الانكليزية } \\
& \text { م.A. عمار احمد هميمود } \\
& \text { قسم الترجمة / كلية الآداب / جامعة الموصل }
\end{aligned}
$$

$$
\text { د. تصميم الغلاف }
$$




\section{قواعد النشر في هبلة آثار الرافدين}

$$
\begin{aligned}
& \text { 1- تقبل المجلة البحوث العلمية التي تقع في تخصصات: } \\
& \text { • علم الاثار بفرعيه القديم والإسلامي • } \\
& \text { • • اللغات القديمة بلهجاتها و الدراسات الدقارنة. } \\
& \text { الكتابات المسمارية و الخطوط القديمة . } \\
& \text { ه الدراسات التاريخية والحضارية . }
\end{aligned}
$$

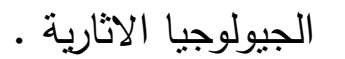

$$
\begin{aligned}
& \text { • تقنيات المسح الاثاري • }
\end{aligned}
$$

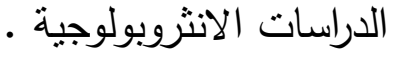

$$
\begin{aligned}
& \text { • الصيانة والتزميم الصنيم }
\end{aligned}
$$

r- تقدم البحوث الى المجلة باللغتين العببية أو الانكليزية .

r-يطبع البحث على ورق (A4)، وبنظام (2010 - word)، وبمسافات مزدوجة بين الاسطر ، وبخط Simplified Arabic للغة العربية، و Times New Roman للغة

$$
\text { الانكليزية، ويسلم على قرص ليزري (CD) ، وبنسختين ورقيتين. }
$$

ع- يطبع عنوان البحث في وسط الصفحة يليه اسم الباحث ودرجته العلمية ومكان عمله

$$
\text { كاملاً والبريد الالكتروني (e-mail) }
$$

0- يجب ان يحتوي البحث ملخصا باللغتين العربية والانكليزية على ان لا تزيد عن (. (1) كلمة.

1-يحتوي ملخص البحث بالإنكليزية على عنوان البحث واسم الباحث ودرجته العلمية ومكان عمله كاملاً والبريد الالكتروني له. V- تضمين البحث كلمات مفتاحية تتعلق بعنوان البحث ومضمونه. ^- ان لا يكون البحث قد تم نشره سابقا أو كان مقدما لنيل درجة علمية أو مستلاً من ملكية

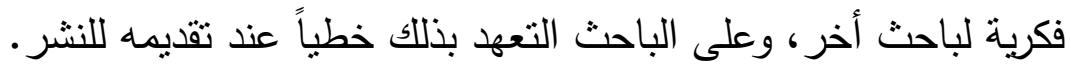
9- يلتزم الباحث باتباع الاسس العلمية السليمة في بحثه. • 1- يلزم الباحث بتعديل فقرات بحثه ليتناسب مع مقترحات الخبراء واسلوب النشر في 
11- لا تتجاوز عدد صفحات البحث عن (ro)، صفحة وفي حال تجاوز العدد المطلوب يتكفل الباحث بدفع مبلغاً اضافياً عن كل صفحة اضافية.

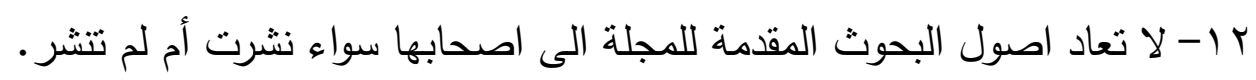
با ا-ترقم الجداول والاشكال على النوالي وبحسب ورودها في البحث، وتزود بعناوين، وتقدم بأوراق منفصلة وتقدم المخططات بالحبر الاسود والصور تكون عالية الدقة. ع ا- تكتب ارقام الهوامش بين قوسين وترد متسلسلة في نهاية البحث. 10-يشار الى اسم المصدر كاملاً في الهامش مع وضع مختصر المصدر بين قوسين في نهاية الهامش.

17 - يتحمل الباحث تصحيح ما يرد في بحثه من اخطاء لغوية وطباعية. V V Vعمل المجلة وفق التمويل الذاتي، ولذلك يتحمل الباحث اجور النشر البالغة

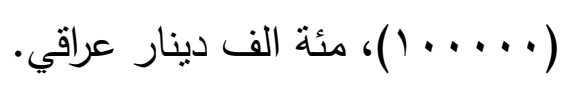

11 ا- يزود كل باحث بمستل من بحثه، أما نسخة المجلة كاملة فتطلب من سكرتارية المجلة لقاء ثمن تحدده هيأة التحرير . 9 ا - ترسل البحوث على البريد الالكتروني للمجلة: uom.atharalrafedain@gmail.com 


\section{ثبت المتويات}

\begin{tabular}{|c|c|c|}
\hline 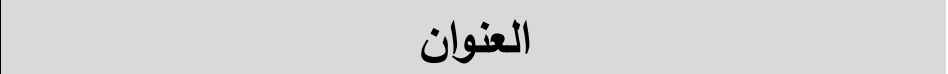 & اسم الباحث & الصفحة \\
\hline توطئة & أ. خالد سالم اسماعيل & 1 \\
\hline من ملاحم ملوك بلاد الرافدين في الألف الثاني والأول قبل & عدي عبدالوهاب النعيمي & $19-4$ \\
\hline "الفِذية" في النصوص الأكّدية & أ. د. فاروق إسماعيل & $\varepsilon \varepsilon-r)$ \\
\hline هواجس خوف الآثوريين وقلقهم من الأرواح الثريرة & أ.ديم محد صالح مصطفى صفوان سامي سعيد & $V \cdot-\varepsilon 0$ \\
\hline مدينة سيواس قبل حكم السلاجقة & أ.د. ياسر عبد الجواد المشهداني & $91-V 1$ \\
\hline التتقيات الروسية في منطقة سنجار شمال العراق & أ. أم.د. محمد كامل روكان & $11 \leq-9 r$ \\
\hline البيوت السكنية من العصر الاشوري الحديث (1) - مواقع منتخبة من منطقة مشروع سد مكحول r آج) & أ.م.د. باسمين عبد الكريم محمد علي السامرائي & $1 r V-110$ \\
\hline من الجوامع التزاثية في مدينة سنجار & أ.م.د حبدر فرحان حسين الصبيحاوي نومان الثمري & $17 \leqslant-119$ \\
\hline 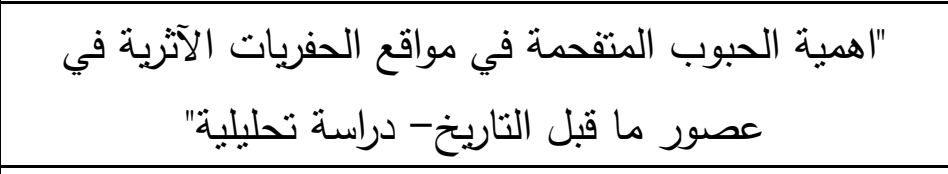 & أ.م.د. حسين يوسف حازم & $110-170$ \\
\hline 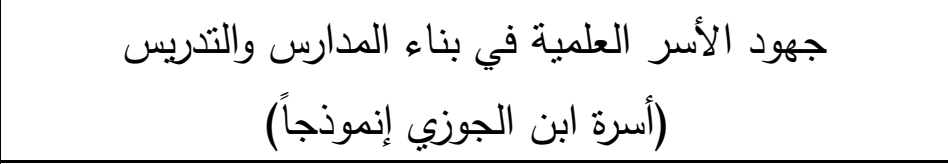 & 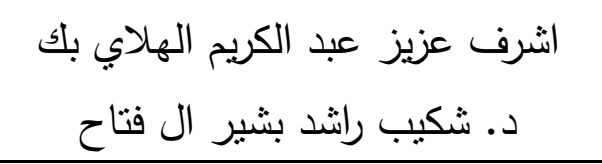 & $r \mid r-I \wedge V$ \\
\hline دوافع تحنيط الحيوانات عند المصريين القدماء & أ.م.د وسناء حسون يونس الاغا & rוT \\
\hline وصولات انجاز اللبن من مدينة بيكاسي " ثل ابوعنتيك" - " & د.آرام جلال حسن الهموندي & rדו-rro \\
\hline نصوص اقتصادية غير منشورة من سلالة اور الثالثة & م.د مهند خلف جمين الثمري & rVq-rqr \\
\hline الثياطين والأرواح الثريرة في العراق القديم في ضوء النصوص المسمارية & مُشتَّى سعدون ظافر الهنداوي & $r \cdot r-r \wedge I$ \\
\hline
\end{tabular}





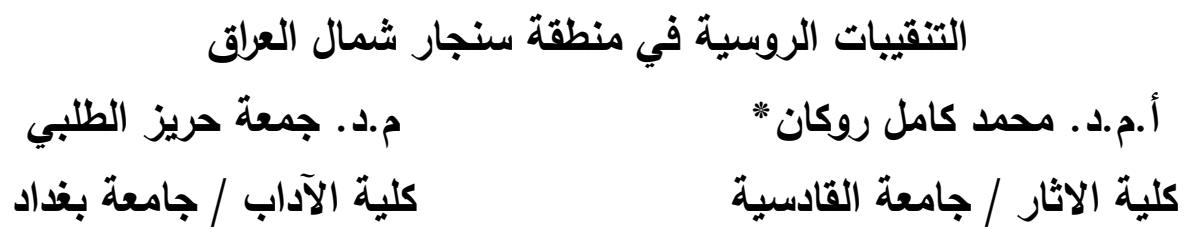

Altalabijumaa@gmail.com

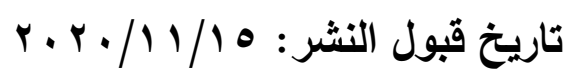
mohammed.rokan@qu.edu.iq

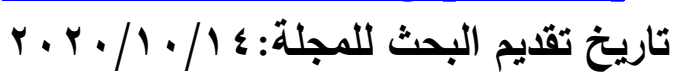

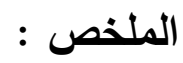

كان للتقبيات الروسية في ستينيات القرن الماضي دور مميزً في الكثف عن حضارة

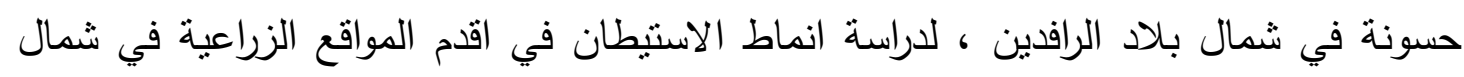

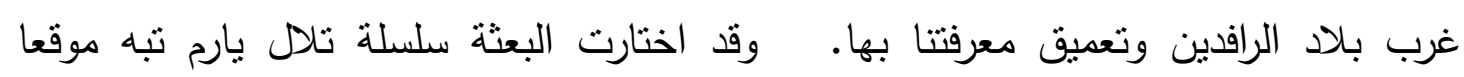

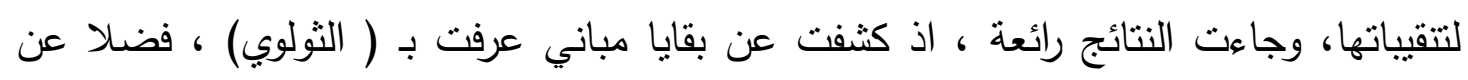

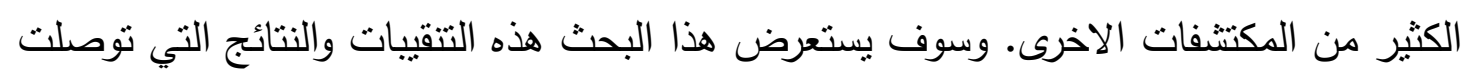
الكلمات المفتاحية : التنقيات الروسية، سنجار، حضارة حسونة، بلاد الرافدين، يارم تبه، الثولوي

\title{
Russian Excavations in Sinjar Region, Northern Iraq
}

\begin{abstract}
:
Russian excavations have played an important role during the sixties in discovering Hassuna civilization in the north of Mesopotamia; which helped to study and enrich our knowledge of different types of settlement in the most ancient agricultural site in the north-west of Mesopotamia.

The excavation mission had chosen the series of Yarem tappeh hill as site for excavation, which came with great results. It discovered the remains of buildings known later as the " Tholoi" in addition to many other discoveries. This paper sheds light on these excavations and shows the results reached.

Keywords: Russian excavations, Sinjar, Hassuna civilization, Mesopotamia, Yarem-tappe ،Tholoui.
\end{abstract}


تعد منطقة سهل سنجار واحدة من أخصب المناطق في شمال العراق قديما، مما جعلها ملائمة للاستيطان منذ أقدم العصور ، تحيط بذه المنطقة الواقعة في غرب الموصل المئات من التلال الأثرية التي تثنل أقدم القرى الزراعية، فضلاً عن عدد من المدن المحصنة التي تؤرخ من

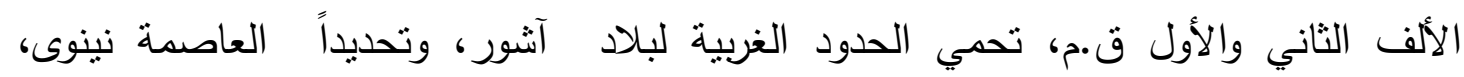
وبالمقارنة مع مناطق أخرى من بلاد الرافدين فإن منطقة سهل سنجار لم تستكثف آثارباً بشكل

بدأت التنقيات الروسية في منطقة سنجار عام 979 (، وكانت الغاية منها دراسة أقدم المواقع الزراعية في شمال العراق، لذا كان التحري مركزاً على الأقسام الثمالية الثرقية من العراق وغرب إيران وجبال كردستان وزاكروس، اذ تعد منطقة شمال - غرب العراق من الموصل إلى سوريا- منطقة مناسبة للارتباط الحضاري بين العراق وسوريا ومناطق البحر المتوسط منذ أقدم العصور، وتقدم المصادر الطبيعية فيها منظوراً خصباً للتحري عن القرى لئرئ الزراعية الاولى. (1)

اختارت البعثة الروسية سلسلة تلال يارم تبه، وهي مجموعة متصلة قطرها نحو ا كم، ثلاث منها كبيرة الحجم، تمثل إلى حدٍ ما مستوطنات من ثناثة عصور مهمة جداً من حضارات الاستيطان الزراعي في شمال بلاد الرافدين هي ؛ حضارة حسونة وحلف والعبيد. (2) ولم تقتصر جهود البعثة الروسية على سلسلة تلال يارم تبه فحسب، بل وسعت عملها في هذه المنطقة وكثفت عن عشرات المستوطنات الصغيرة ايضا، ونقبت في ثلاثة مواقع منها؛ تل سوتو، تل كول تبة، والمغزلية، وقد كثفت الطبقات السفلى في هذه المواقع أنها تعود إلى دور حضاري أقدم من دور حسونة، أطلق عليه تسمية دور ما قبل حسونة أو دور سوتو - أم الدباغية. (3)

\section{طبوغرافية منطقة سنجار:}

تقع منطقة سنجار في منطقة الجزبرة، التي تقع بين أعالي دجلة والفرات، تحدها الأنهار من جهتين وتحدها من الثمال سلاسل جبلية ( الثكل (). إن الدائرة الواسعة المتكونة من النهرين دجلة والفرات تجعل القسم العلوي لبلاد الرافدين على شكل جزيرة، يطلق عليها فعلاً اسم (الجزيرة) في الوقت الحاضر (4)، اذ تعد هذه المنطقة من الناحية الطبوغرافية أو التضاريسية جزءأ من هضبة جزيرة العرب، وتحتوي على عدد من الأحواض الصغيرة المقفلة التي لا مخرج لها، أكبرها وادٍ طويل ضيق يقطع الهضبة عميقاً يعرف بوادي الثرثار ، تتصل به عدد من الجداول، 


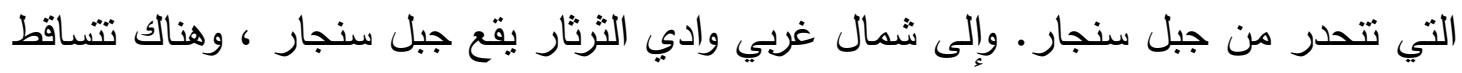

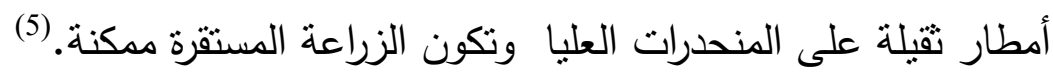
تقسم سلسلة جبال سنجار منطقة الجزيرة إلى قسمين غير منتظمين، وتمتد هذه السلسلة السيلة الجبلية باتجاه الغرب لتتكل جبل عبد العزيز في سوريا. وتقع إلى الثمال من هذه السلسلة

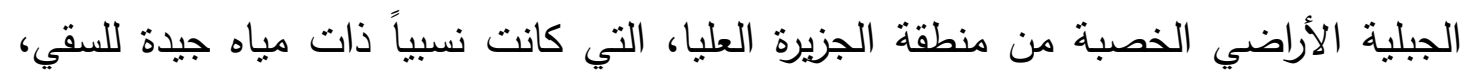

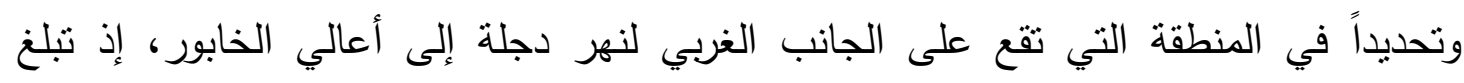

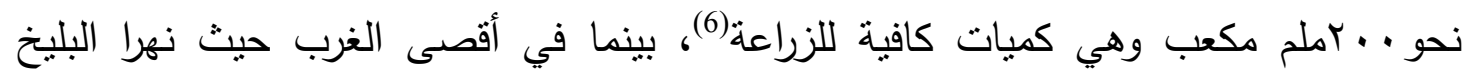

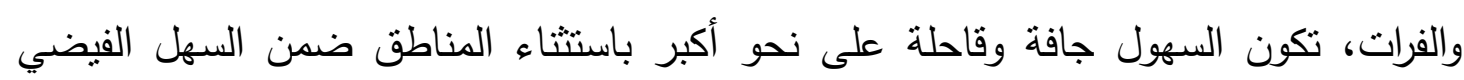

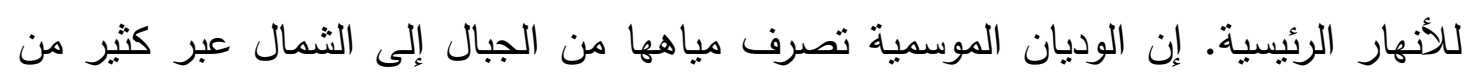
الأراضي. تتألف منطقة الجزيرة من السهول الملتفة في شمال سوريا وشمال العراق، ومن سفوح

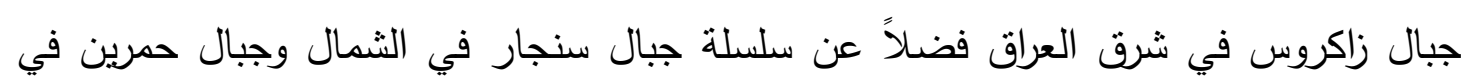

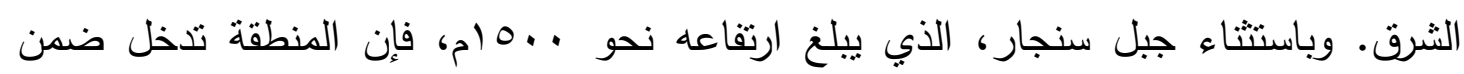

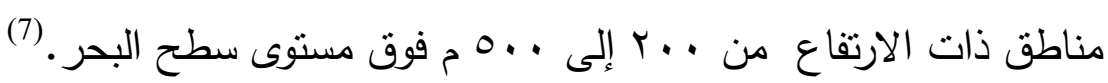

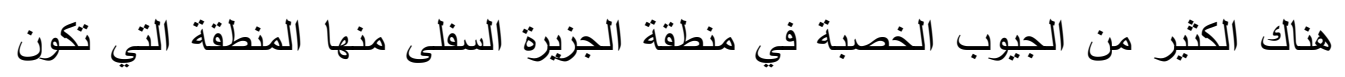
مباشرة إلى الجنوب من جبل سنجار والمناطق التي حولها، حيث ملتقى كل من نهري البليخ

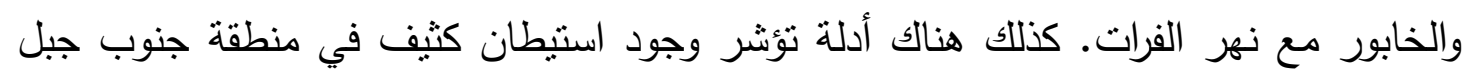

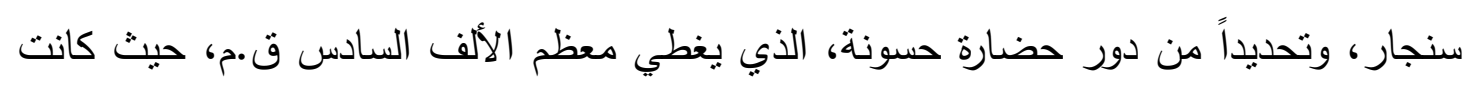

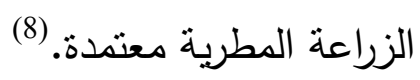
عموماً فإن المنطقة بمحاذاة نهري الخابور والبليخ نتسع فيها الأراضي الصالحة للزراعة وتتصل من الأعلى بالأراضي الواقعة على سفوح جبال طوروس، إذ ساعدت معدلات سقوط الأمطار

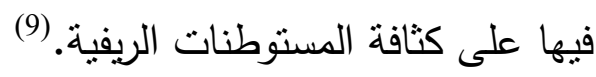
يخترق الجزء الأعلى من نهر الفرات منطقة الجزيرة من الثمال عبر الحدود التركية،

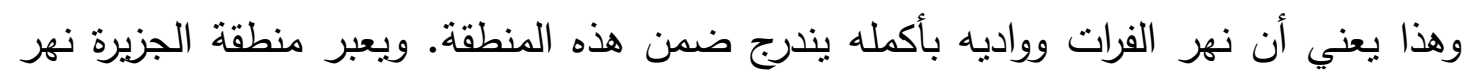

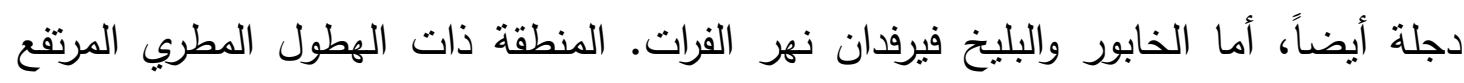

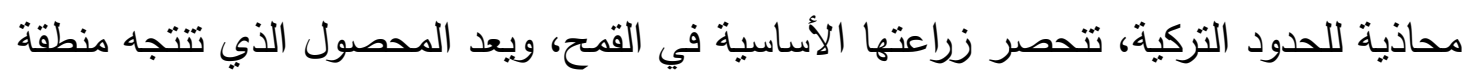

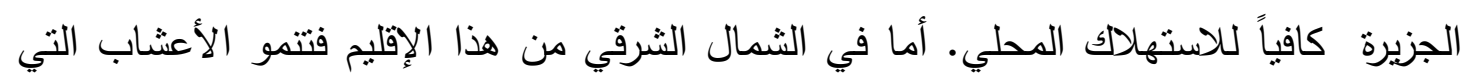
تتنمي إلى المجموعات شبه الجافة حيث نطاق الزراعة الواسعة والممكنة، تنمو نباتات النطاق 
القاري لشمال شرق سوريا، ونباتات النطاق السهبي السوري في بقية أجزاء الإقليم المقاومة للجفاف والملوحة. (10)

مع توجه الإنسان في عصور ما قبل التأربخ إلى ممارسة الزراعة، فقد أصبحت أهميتها تزداد في مجتمعات هذه المرحلة، لذا فإن الأراضي الخصبة في السهول الثمالية والثرقية وسفوحها أصبحت ذات أهمية كاملة.

كان معدل الأمطار السنوي في هذه المناطق كافياً للزراعة المطرية، ضمن الأجزاء الثمالية والثرقية للسهول العليا، التي تستقبل معدل مطري أكبر من المناطق الجنوبية والغربية. الاختلافات الموسمية والسنوية تؤثز بشكل كبير في الحدود الواضحة أو الدقيقة للزراعة المطرية حول أطراف السهول إلى الجنوب والشرق، يمتذ النبات الطبيعي في مناطق السهول بتتوع من الحشائش إلى النباتات المغذية، والنباتات الغنية للفلاحة، والمغذية للحيوانات المدجنة والمتوحشة التي يصطادها الإنسان. بشكل عام تعد منطقة الجزيرة ومنها منطقة سنجار جزءأ من الإقليم الطبيعي الممت من

جبال طوروس في الثمال الغربي. (11) أنماط الاستيطان في منطقة سنجار: تشكل منطقة سنجار موطن حضارة حسونة الثهيرة في الألف السادس ق.م، إذ كثف فيها عن سلسلة من المواقع المميزة منها؛ أم الدباغية، يارم تبه، كول تبة و سوتو وغيرها (الثكل r). إن معظم مواقع هذه المنطقة تقع ضمن الخط المطري أكثر من .r ملم مكعب، ما عدا موقع أم الدباغية، لقد أسست معظم مواقع هذه المنطقة على الأرض البكر، وليس هنالك أي مون موقع تتوافر فيه سكنى مستمرة من العصر الحجري الحديث ما قبل الفخار إلى العصر الحجري

الحديث الفخاري، إذ أن أقدم دليل منوافر هو فخاريات تعود بتأربخها إلى العصر الأخير. (12) إن مستوى نظام الاستيطان في هذه المنطقة مكون من نظام الاستيطان البسيط؛ وهو نظام يتألف من مستويين من المستوطنات: المستوى الأول تمتله القرى دائمة السكن، وهي مستوطنات تسكن طوال السنة، وعادة ما تكون المناطق المفضلة للعيش في منطقة الزراعة الديمية، وقريبة من مصادر المياه الدائمة مثل مواقع يارم تبه، تل سوتو، تلول الثناثات، بينما تمثل المستوى الثاني قرى صغيرة مرتبطة بالمستوطنات الدائمة، وعادة ما تسكن لمدة معينة مؤقتة من السنة من

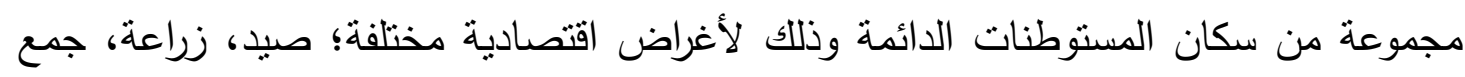
طعام نباتي بري، أخشاب ... إلخ. وتقع مناطق الاستثمار التي توجد فيها هذه المستوطنات إما في المناطق المفضلة للعيش أو على أطراف منطقتين مختلفتين بيئياً؛ مناطق جبال، وديان، 
مجاري أنهار ، وسهوب جافة. ولا تبعد هذه المناطق كثيراً عن المستوطنات الدائمة، لذا يتمكن

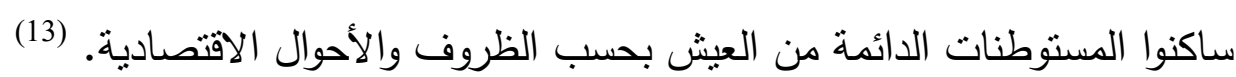

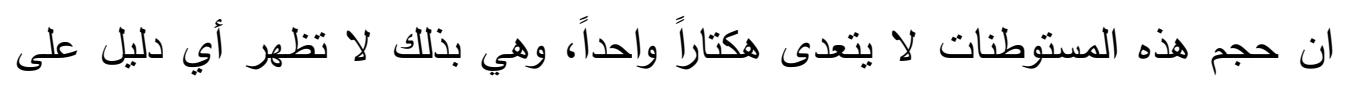

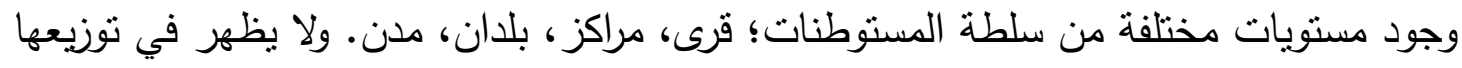
أي نوع من نظام الاستيطان، الذي يعتمد في تحديده على الاختلاف في أحجام المستوطنات وموضعها والعلاقات بينها وقياس درجة التبعية لسلطة المراكز الكبيرة؛ دينية و اقتصادية،

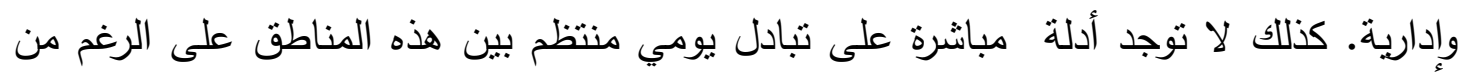

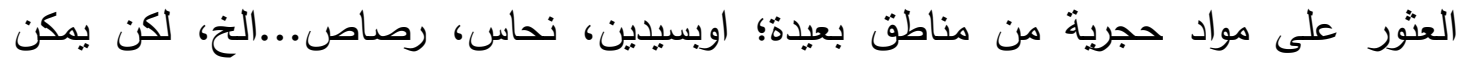
الافتراض بوجود صلات قرابة بين ساكني المستوطنات في منطقة واحدة ( صغيرة)، فيلة فربما ينتمون إلى عوائل كبيرة أو عشيرة، وربما أن البعض من هذه المستوطنات تكونت نتيجة لئنة زيادة السكان وانفصال مجموعة من ساكني هذه المستوطنات بسبب الضغط السكاني على كميات الطعام التي يمكن الحصول عليها من المناطق المحيطة بالمستوطنات، وتكوين مواقع جديدة

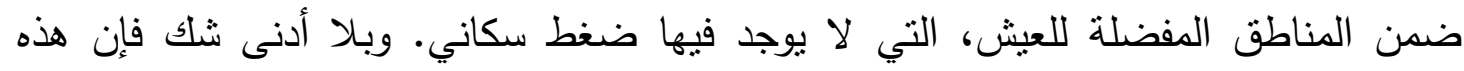

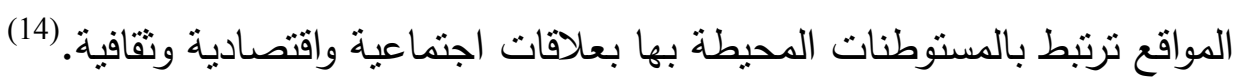

\section{التققيبات الروسية في منطقة سنجار:}

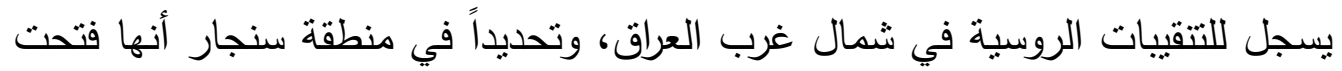

آفاقاً جديدة ترتبط بحضارة حسونة، إذ أنها كثفت عن معالم جديدة لهذه الحضارة.

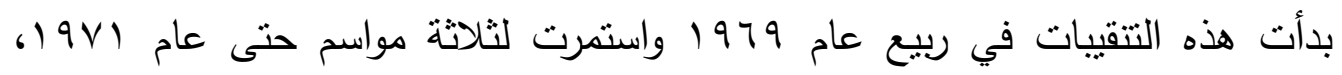
وكانت الغاية منها دراسة أقدم المواقع الزراعية في شمال - غرب العراق كما أثرنا في أعلاه.

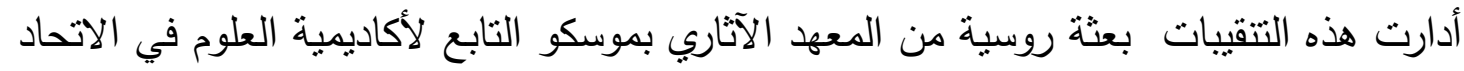

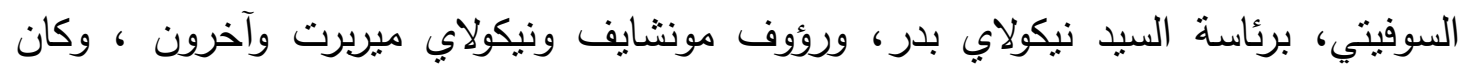

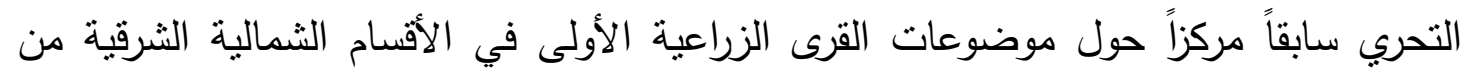

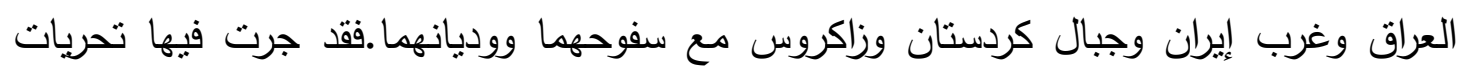

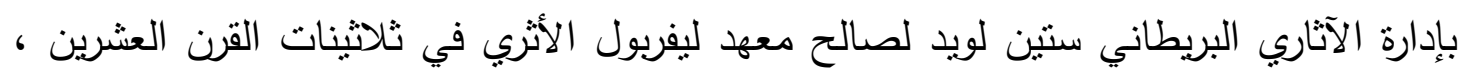

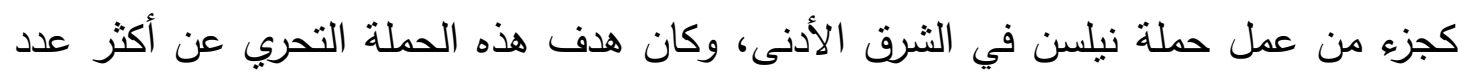

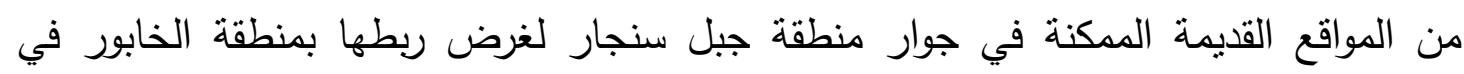

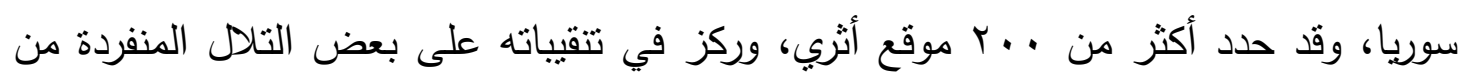

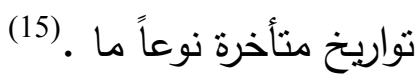


اختارت البعثة الروسية سلسلة تلال يارم تبه ( الثكل ب )، حيث جاء اسم الموقع من كلمة تركية تعني نصف التل، إذ أن النصف الثاني من تلال يارم تبه دمرته التعرية النهرية، لذلك سمي الموقع بهذا الاسم. تقع هذه السلسلة من التلال في سهل سنجار على بعد Y-V كم إلى الجنوب الغربي من قضاء تلعفر ، وتتألف من ستة تلال تمتذ مسافة كيلومنز واحد على جانبي نهر صغير يسمى نهر آبري، ثناثة منها على كل جانب. (16)

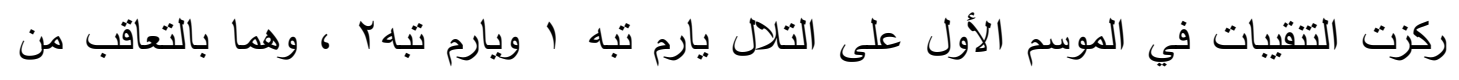
حضارة حسونة وحضارة حلف ، يقع يارم تبه ا في أقصى الثرق من سلسلة التلال، وتقدر

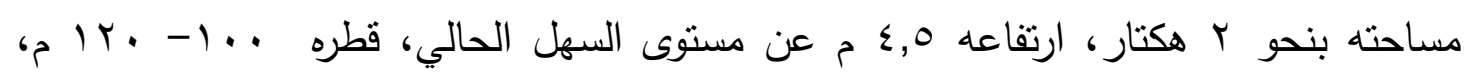

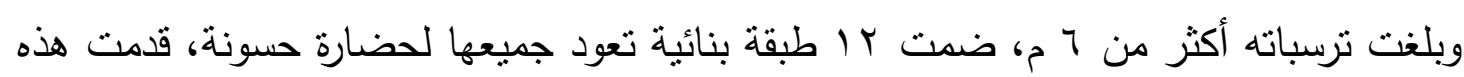
التلال مواد أثرية أظهرت بأنها تمنت إلى حدٍ ما مستوطنات من ثناثنة أدوار حضارية مهمة جداً من حضارات الاسنيطان الزراعي في شمال الرافدين، هي: حضارة حسونة وحلف والعبيد. (17) قدمت الطبقة rا أقدم الأمثلة عن الاستيطان المستقر تمنلت بقاياه بمبانٍ ذات غرف متعددة كبيرة، منها مبان مستطيلة الثكل وأخرى دائرية، إذ كثف عن ثلاث مبان مركبة، ومبان أخرى

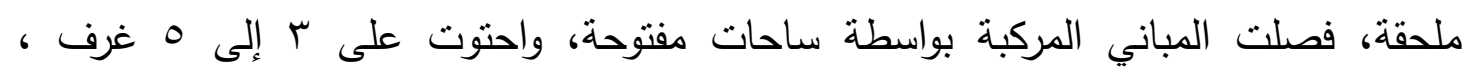
مخططاتها بقياس r × X م ، وجدرانها بسمك هب سم، بنيت بكتل الطوف، كما هي الحال في جميع طبقات الموقع، وضعت على طبقات من حصر السعف أو القصب، وكانت هناك أفران ترتبط بها تقع خارج الغرف، كما وجدت مباني دائرية غير اعتيادية بقطر ب, 0-r م في النهاية الثمالية، تشير محتوياتها إلى وظيفة غير منزلية. استمر هذا النوع من العمارة في الطبقات

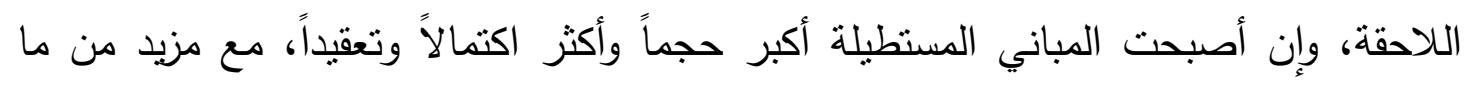
يعرف بمصاطب التجفيف ومخازن الحبوب وأفران مستطيلة ودائربة، منها أفران بطابقين هي الأقدم في تاريخ بلاد الرافدين، والأكثر أهمية ظهور مبان مستطيلة متحدة مع مبان دائرية في

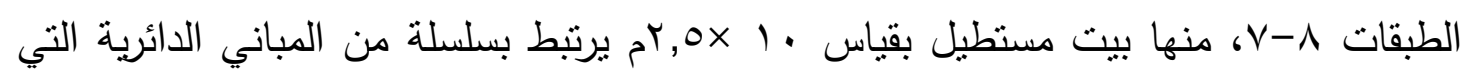
تحيط به من جميع الجوانب، ربما كان لبعضها سقف مقبب، كما عززت الجدران من خلال ما

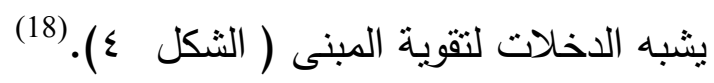
حصلت نطورات واضحة في مباني الموقع في الطبقة السادسة من ناحية كبر حجم المباني وضخامتها، وتعدد الغرف فيها(19)، ويبدو أنه حتى في المراحل المتأخرة من السكنى فإن المنطقة المركزية من المستوطن بقيت خالية من المباني الأساسية ، ولو أنه يبدو أن المركز تحرك نحو جهة الثرق من المستوطن ( الثكل 0 )(20)، كثف في النهاية الثمالية من المستوطن في الطبقة الخامسة عن مجمع خزن كبير بطول نحو 17 م وعرض 7 م متجه من

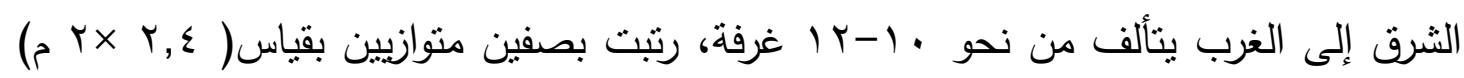




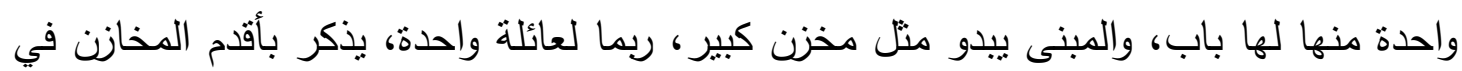

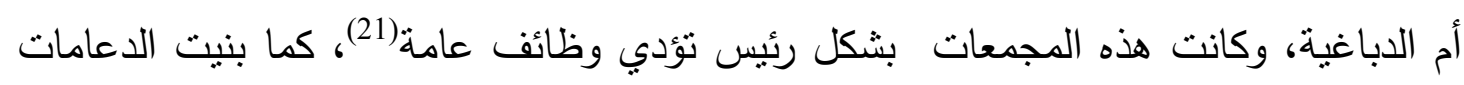

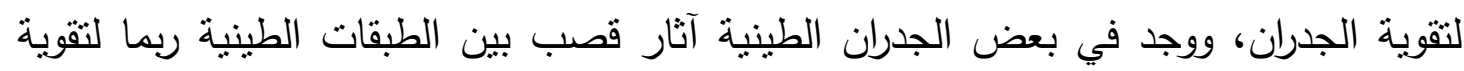

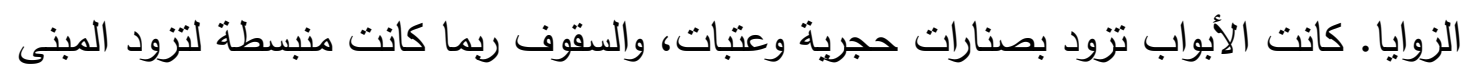
بمساحة عمل اضافية لتنظيف وتجفيف الحبوب وأعمال منزلية أخرى. (22)

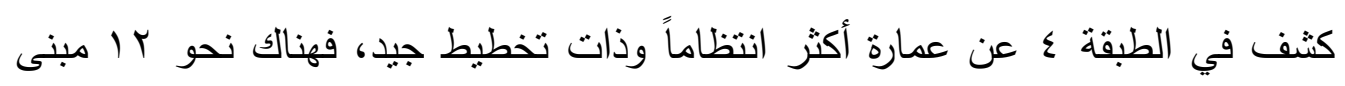

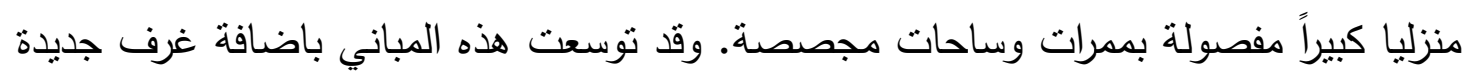

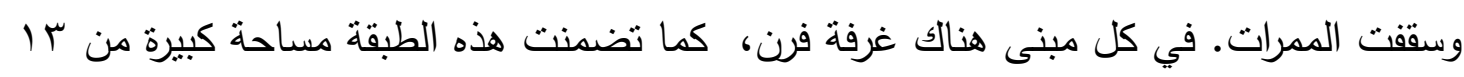

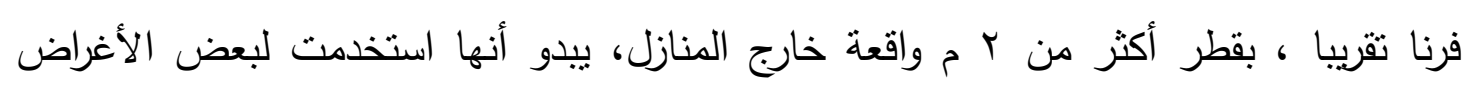

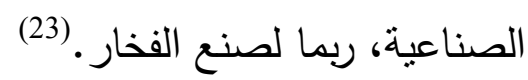
وظهرت مرة أخرى في الطبقات من r-1 مبان مستطبلة متعددة الغرف مرتبطة بممرات

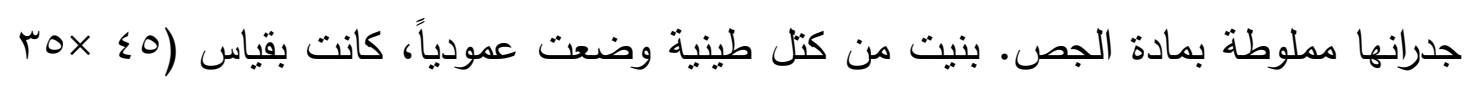

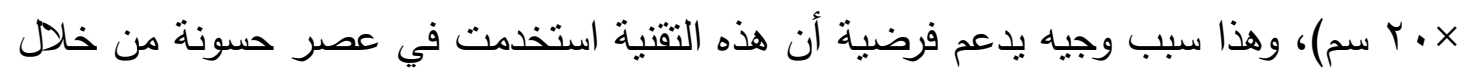
تتكيل كتل طينية قياسية، وقد أدت هذه العملية في النهاية إلى شيوع استخدام الآجر الطيني. تشكي قدم موقع يارم تبه ا بشكل عام مثالاً جيداً عن تطور مثالي لمستوطنة بدأت بإنشاء عدد

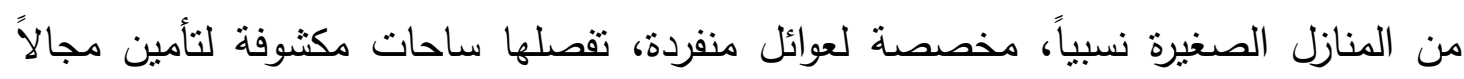

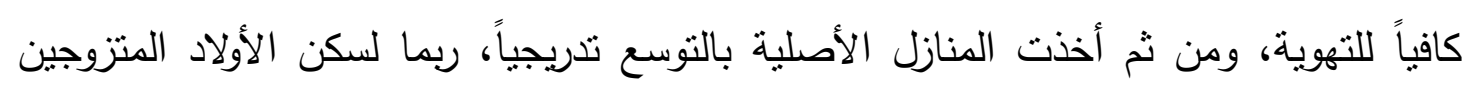

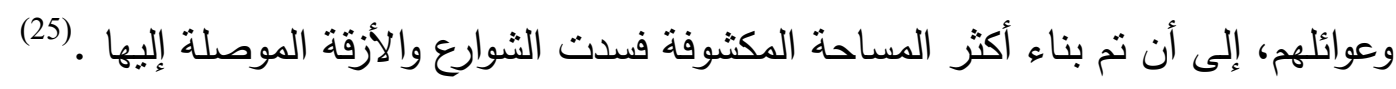

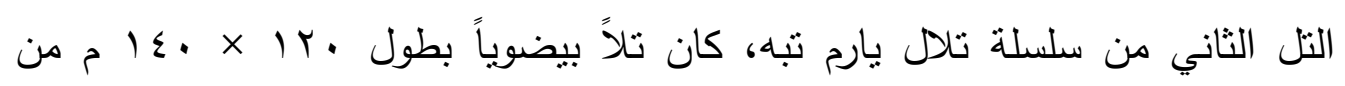

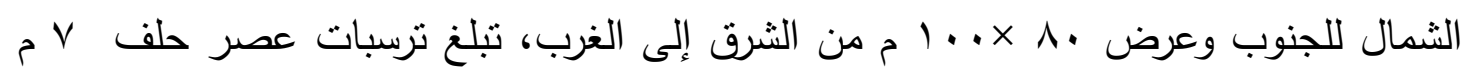

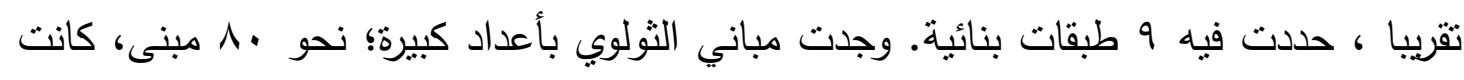

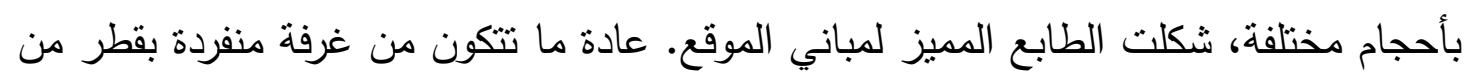

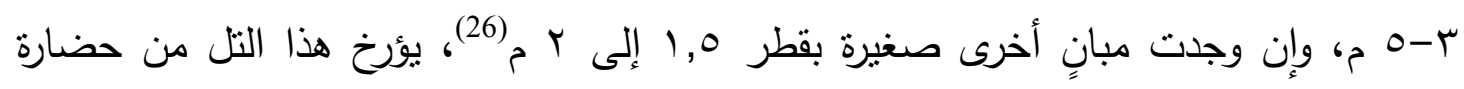
حلف، وتعكس المباني فيه التطورات المحلية في مجال العمارة، فجميع الطبقات تميزت بلمبل بالمباني

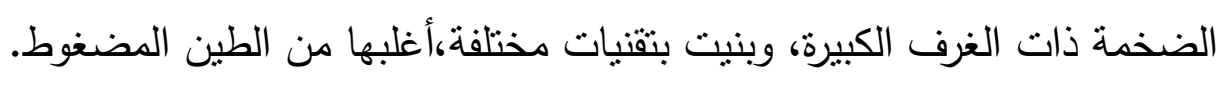
تكونت هذه المباني في الطبقات الأقدم بشكل عام من غرف دائرية منفردة، بينما في الطبقات

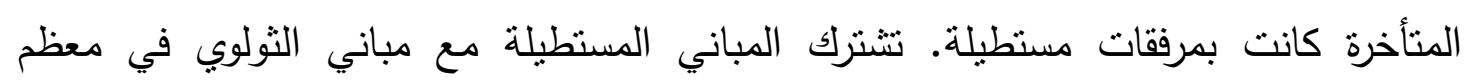

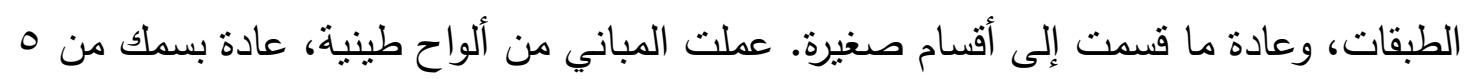


إلى 7 سم، لكنها تصل إلى أكثز من 01 × × × × • سم في حجمها، وكانت تطلى بطبقة من الطين نحو r,0 سم، وهي أكثر ملاعمة من الآجر الطيني (27)، ضمت الطبقة 9 عدة منشآت بنائية تقع مباشرة على الأرض البكر، منها؛ مبان مستطيلة متعددة الغرف، وجدت فيها أفران، فضلاً عن مجموعة من مباني الثولوي، بعضها بأفران داخلية، ربما كانت تستخدم للسكن. مبنى مبلى مبان الثولوي الأكبر كان بقطر ب,0 م، وضع على مصطبة طينية، له جدران طينية صلبة جداً عرضها ، •ـ سم بنيت كلياً من الطوف، ربما كان ذا وظيفية طقسية كما تشير إلى ذللك محتوياته، التي وجد بعضها أسفل الأرضية، ويحتمل أن له سقفاً مقباً،عمل من القصب وغطي بطبقة من الطين، كما وجدت في هذه الطبقة عدة حفر غاطسة في الأرض البكر وأفران بطابقين. (28) استمرت المباني في الطبقات الأخرى بمخططاتها المستطيلة والدائرية. ففي الطبقة 7 من يارم تبه Y هناك مجموعة من المباني الدائرية ( الثكل جائ)، عادة كانت صغيرة الحجم ، بنيت من

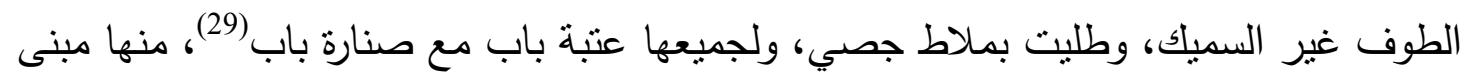
غير اعتيادي يقع ضمن مبنى كبير بمخطط منصالب (بشكل صليب)، قطره نحو ج,r م، وسمك جدرانه • ج إلى • V سم، قسمت الجدران الداخلية لله إلى نصفين، النصف الثمالي قسم إلى ثلاث غرف صغيرة، وتقع إلى جواره سلسلة من غرف مستطيلة صغيرة وممرات، ربما تشكل جميعها مخزناً كبيراً في وسط المستوطن. وهنالك أجزاء صغيرة من جدران منحنية منوازية، ربما استخدمت كمصاطب للتجفيف أو مخازن، إذ سبق وأن ظهر منلها في موقع يارم تبه ا(30)، وظهرت في الطبقة الرابعة ستة بيوت استخدمت للسكن وليس للخزن بدليل العثور على مواقد وأدوات منزلية، فضلاً عن جدار ضخم غير اعتيادي بطول ^,ء م، مطلي بطلاء خفيف ودعامات إضافية ربما يعود إلى مبنى بوظيفة عامة. (31)

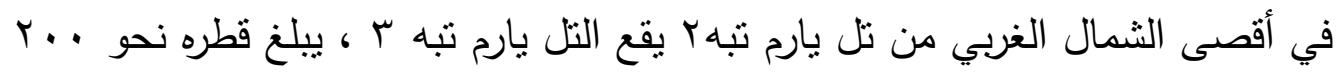
م، ويرتقع نحو Y ام، وهو الأكبر بين مجموعة تلال يارم تبه، كثف فيه عن تسع طبقات بنائية جميعها من عصر حلف، ضمت بقايا عمارة لا تختلف عن ما موجود في موقع يارم تبه ب، فهنالك مباني الثولوي بأنواع مختلفة، احتوى بعضها غرف داخلية صغيرة ومعالم خاصة، إحداها

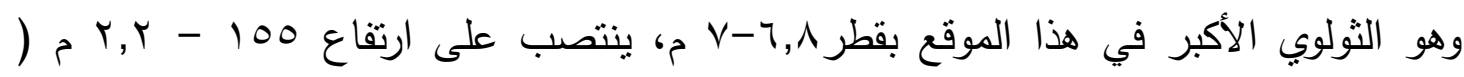

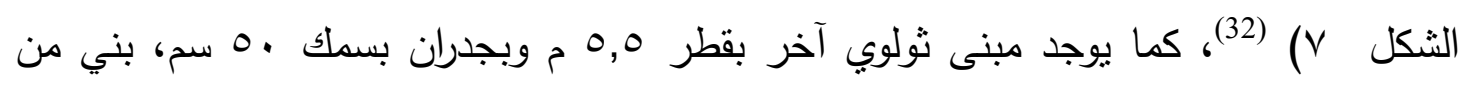
الطوف مع القش وطلي بطبقة خفيفة من الملاط الطيني، وفي مقابل الجوانب من الداخل بنيت جدران بزوايا مستقيمة، لتجعل المخطط الداخلي بشكل صليب، وهو لا يشبه العديد من المباني

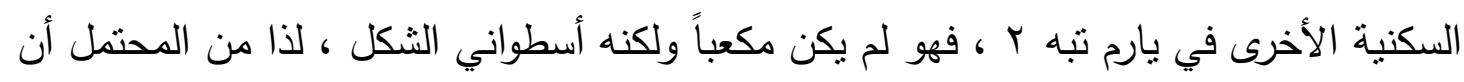
يكون له سقاً مستوياً. محتويات هذه المباني تؤشر وظيفة منزلية، إذ كانت التتانير جزءً من هذه 
المباني. كذلك وجدت مبان مستطيلة، بعض محتوياتها تشير إلى أن لها وظيفة مخازن للحبوب. (33)

لم تقتصر جهود وأعمال البعثة الروسية على مواقع البحث في يارم تبه كما أثنرنا في

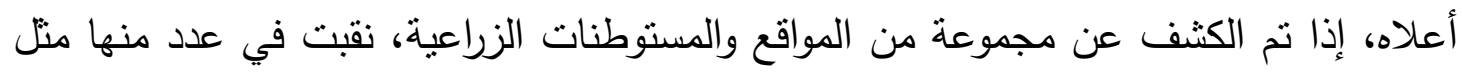

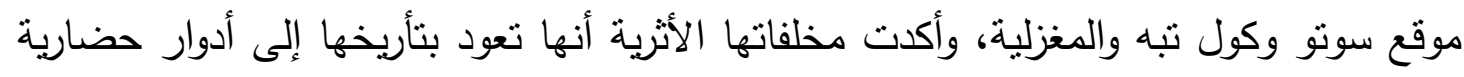
تسبق دور حضارة حسونة. وقد أكدت أعمال التحري والتتقيب في تل سوتو وموقع المغزلية، أنهما كانا من المواقع

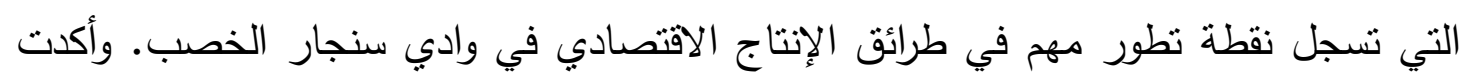

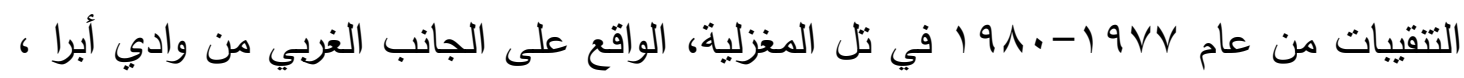

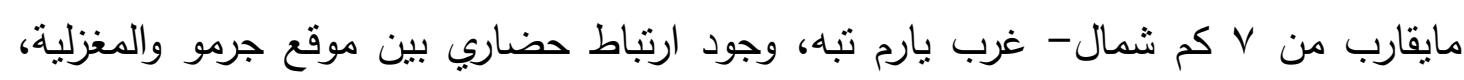

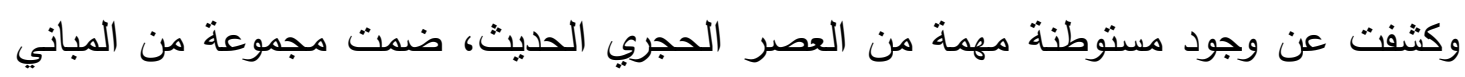

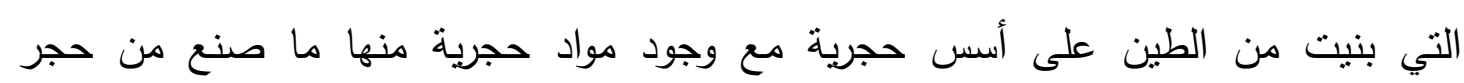

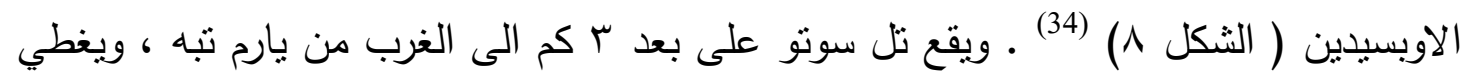

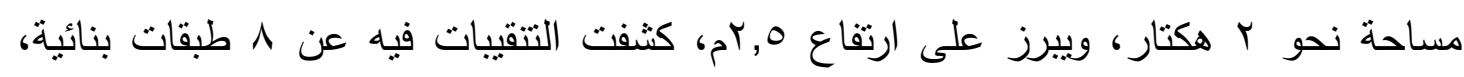

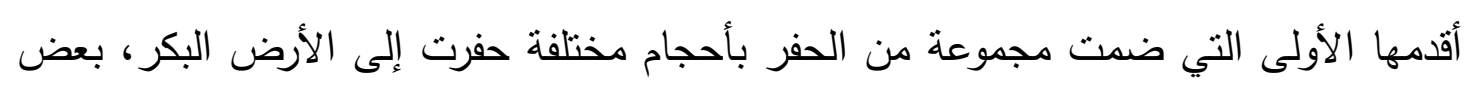

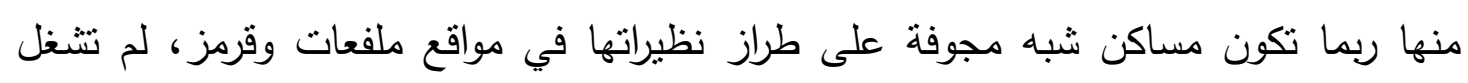

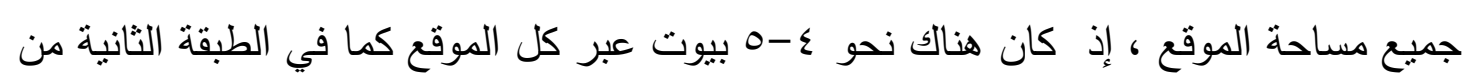

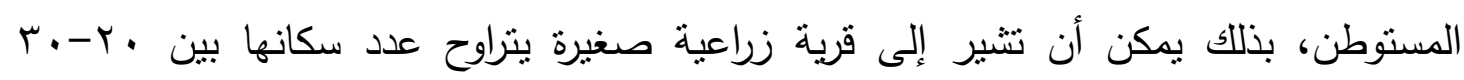
شخصاً (الثكل 9).

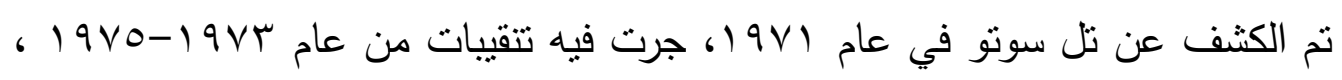
وبدأ الحفر في القسم الثرقي من التل وكثف عن طبقات تعود لعصر ما قبل حسونة، كانت

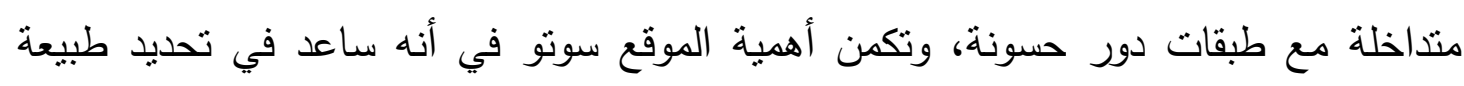

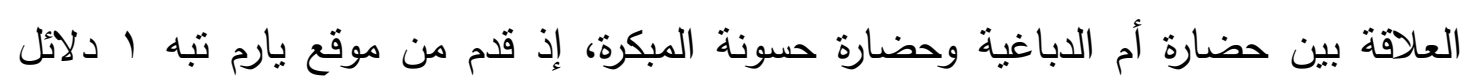

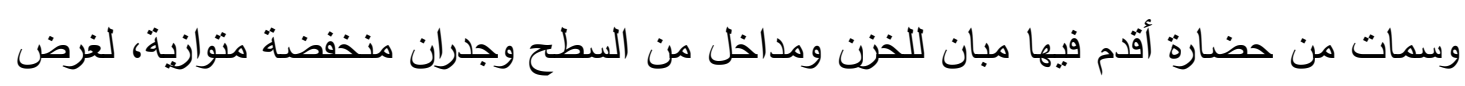
التجفيف وغيرها من المتتشابهات. (36)

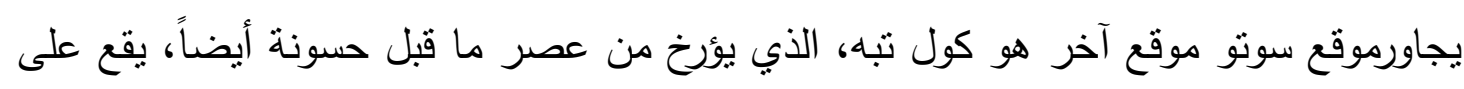

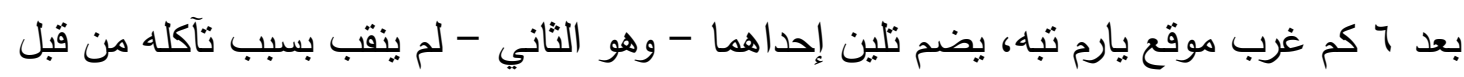

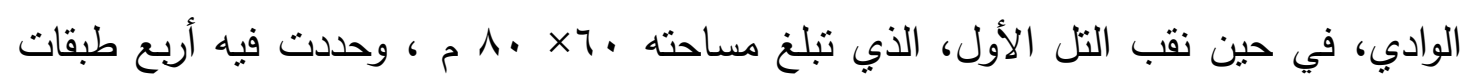

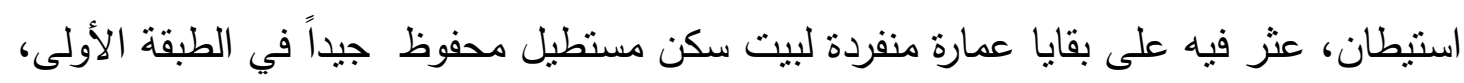


يغطي مساحة ع ا م مربع مع مقصورات (غرف صغيرة للخزن) ( الثكل (1)، وآنية كبيرة حفرت على الأرضية(37)، يثبه هذا البيت نظيراته في سوتو وأم الدباغبة، ينقسم إلى ثناثة أقنام بمدخل رئيس عرضه الأصلي (م، قلص فيما بعد إلى . . سم، يقع في أحد الجدران القصيرة. وهناك مبانٍ مستطيلة تجاور هذا البيت، وجدت تحت أرضية واحد منها ثلاث آنية رخامية. جميع مباني الطبقة الأولى بنيت مباشرة إلى القاع الحجري ولها أرضيات طينية سميكة، بنيت الجدران من الطوف في جميع الطبقات وكانت بشكل عام بسمك . عـ سم. الطبقات ب-ـ لـ تحفظ جيداً

وقد ضمت مباني مستطيلة صغيرة بأرضيات مطلية بمادة الجص أعيد بناؤها عدة مرات. (38) لقد اثبتت التقبيات في سوتو وكول تبة ويارم تبه بشكل مقنع بأن جذور مواد حضارة حسونة كانت وعلى نحو كبير قد وجدت في تطورات سابقة في شمال بلاد وادي الرافدين.

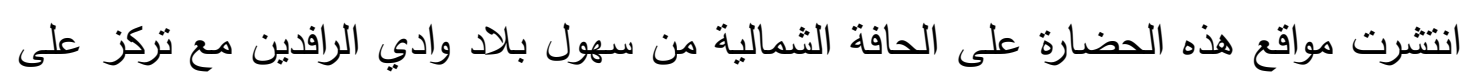
نهر دجلة ومناطق إلى الغرب منه، مع بعض الحضور الثانوي في شرقه، وامتدت إلى الثمال

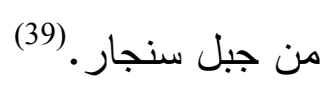
الخلاصة: مان

يشير عالم الآثار الروسي دياكونوف بأنه :" بعد التطور الذي حصل وإقامة اقتصاد توسيع

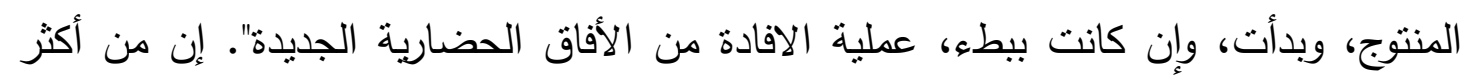
مظاهر هذه العملية بروزاً هو انطلاق سكان جبال زاكروس وسنجار إلى رحاب سهول شمال ما بال وراء بلاد الرافدين، اذ بدأت عملية الاستثمار المكثف للأراضي الخصبة الجديدة، الأمر الذي ميز بشكل ملحوظ كل مسيرة التطور الثقافي لمجموعات المزارعين ومربي الماثية المحليين وجعلها قربية جداً من عتبة الحضارة. (40) ا. كانت منطقة جزيرة الموصل بامتداد الحدود السورية ومنها منطقة سنجار على وجه التحديد الوجهة الرئيسة لسكان الجبال لتأسيس مستوطنات جديدة قائمة على اقتصاد زراعي شغلت حقبة الألف السادس قبل الميلاد، الذي يمنل مرحلة العصر الحجري الحديث الفخاري. r. ظهرت مواقع هذه الحقبة الحضارية في منطقة الزراعة الديمية / منطقة الخط المطري التي تصييها أمطار سنوية لا يقل معدلها عن . ro ملم مكعب، وتحديداً في منطقة الجزيرة ومنها منطقة سنجار • إن توزيع مواضع المستوطنات يظهر عليه النمط المتتانز/ المتباعد (Desperrepattern) الشرق الأدنى بشكل عام، لكن في منطقة سنجار نجد سيادة النمط المتكتل/ مهاد

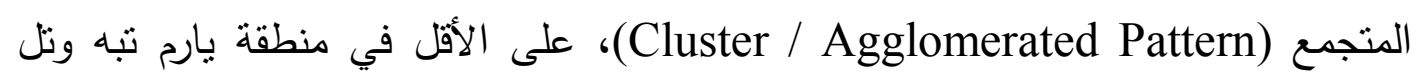
سوتو وكول تبه، وإن ذلك يرتبط بطريقة استثمار الأرض (Land Use)، أو يعتمد على لئ 
الظروف البيئية والمستوى التكنولوجي، وقد أسست جميع المواقع المنقبة في منطقة سنجار -

$$
\text { تلعفر أول مرة على الأرض البكر كما أنشرنا في مواضع سابقة. }
$$

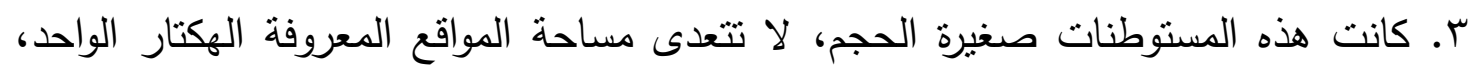

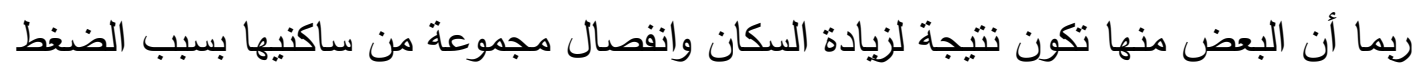
السكاني على كمية الطعام الذي يمكن الحصول عليه من المناطق المحيطة بالمسنوطنات؛

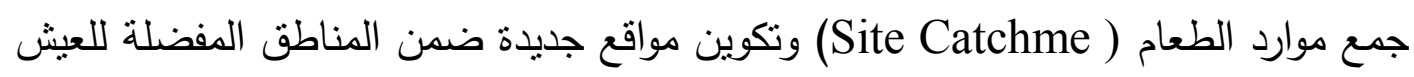

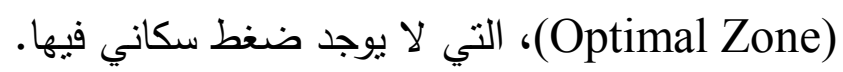
ع. هذه المواقع الجديدة نرتبط بالمستوطنات المحيطة بها بعلاقات زواج أو قرابة وهذا. ونده العلاقات

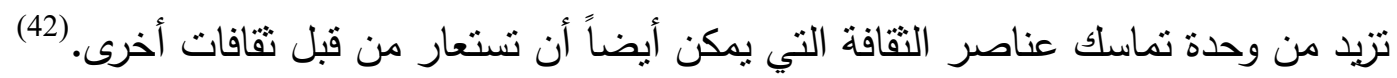

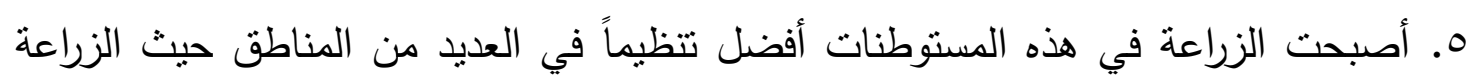

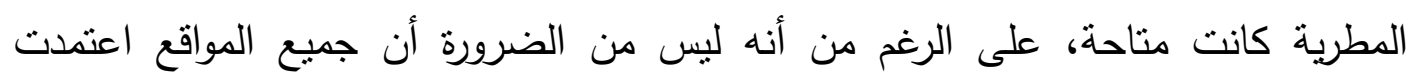

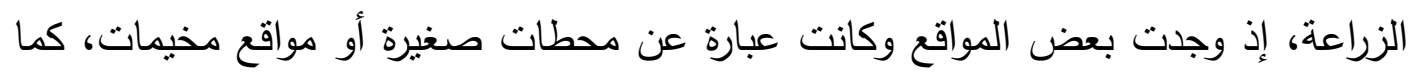

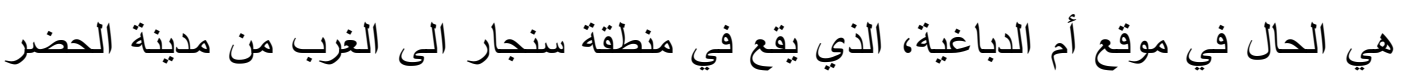
شمال غرب العراق. أن بعض المواضع التي أسست في العصر السابق أصبحت أقرب إلى أن تكون مستوطنات

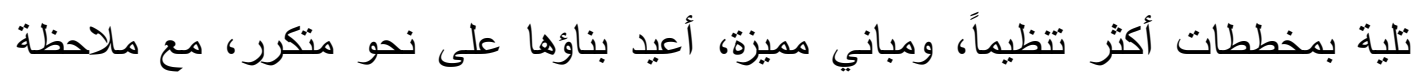

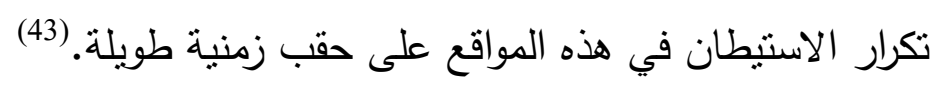

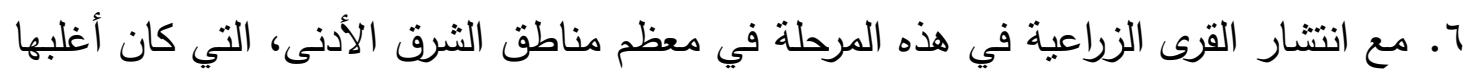

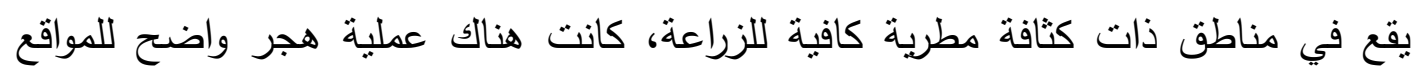

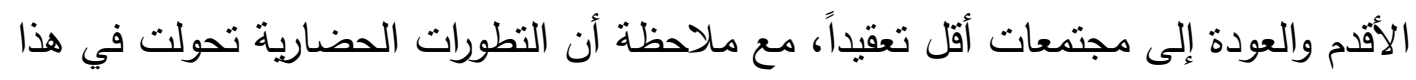

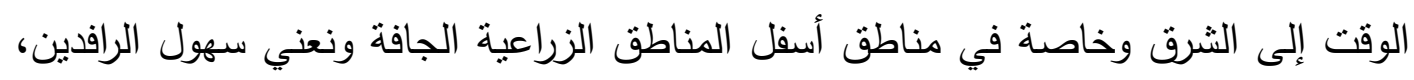

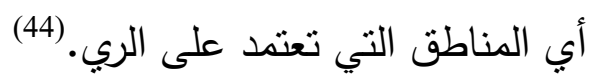

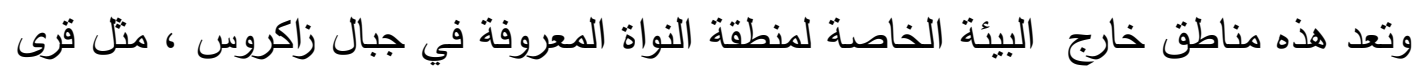
حسونة ومواقع سهل سنجار ، وهي مناطق تقع خارج الحدود المطرية، وهذا يعني استعمال

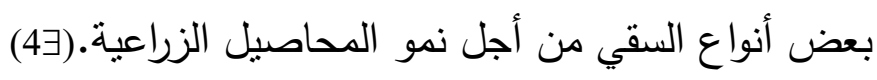

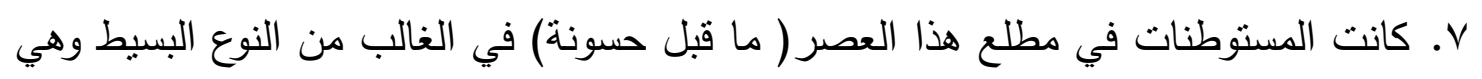

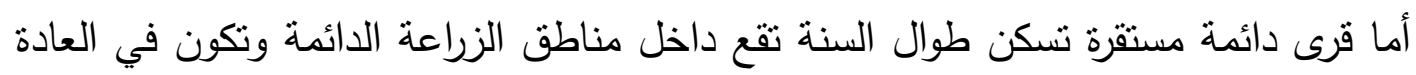
قريبة من مصادر المياه الدائمة مثل سوتو وتلول الثلاثات وكثكشوك بـأ أو أنها موسمية، وهي قرى صغيرة ترتبط بمستوطنات دائمة قريبة نسكن لمدة معينة من السنة ربما من قبل ولئ 
سكان الدائمة لغرض افتصادي مثل الزراعة أو الصيد مثل أم الدباغية، عموماً ليس هناك

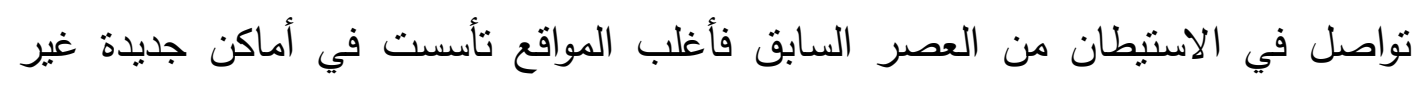

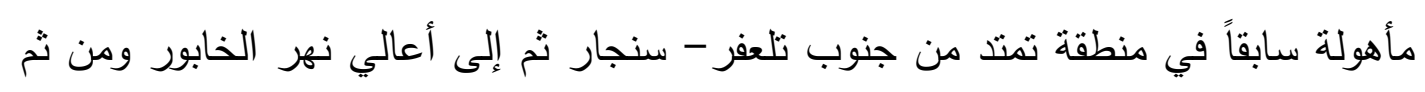
إلى أعالي وادي الباليخ. ^. لقد أكدت نتائج التتقيات الروسية المنتظمة ذات الطابع العلمي على معظم ما أثرنا إليه

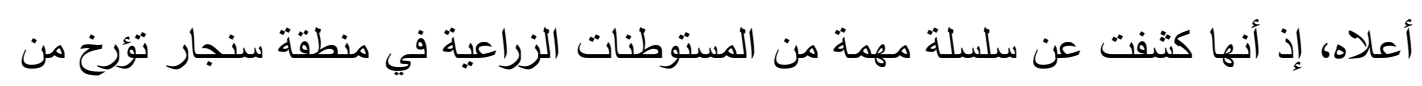

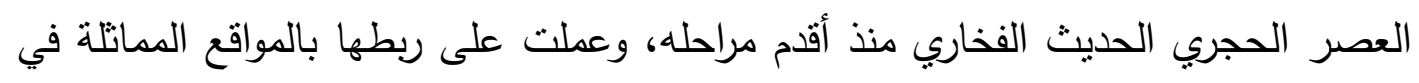
وادي الخابور والباليخ في سوريا، فالمنطقة التي عملوا فيها كانت منطقة مناسبة للارتباط

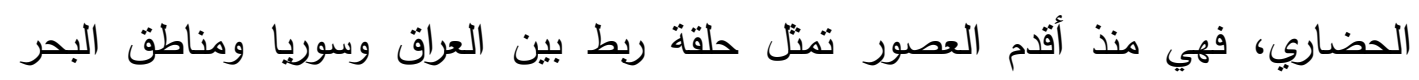

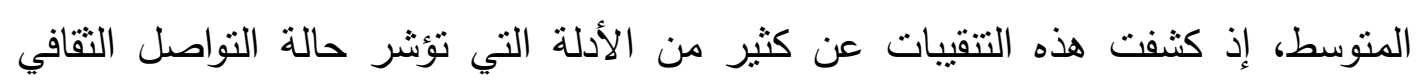

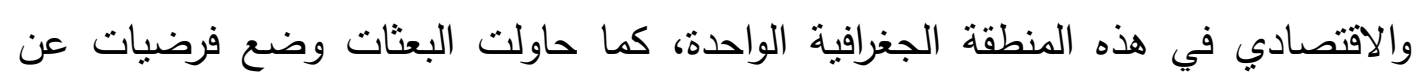

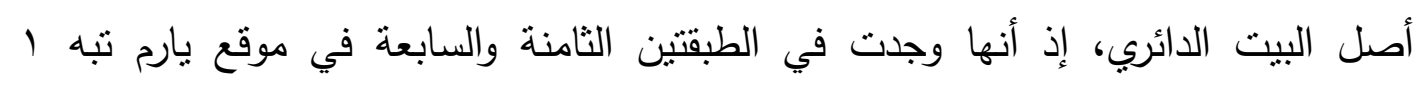

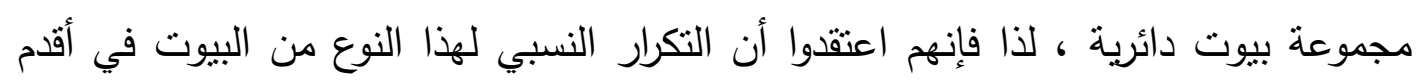

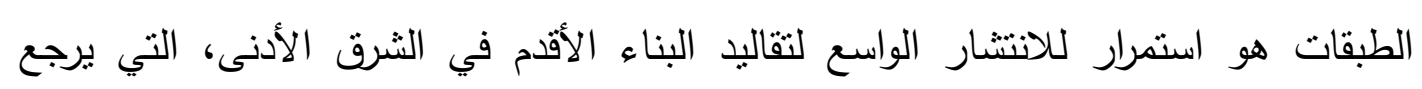

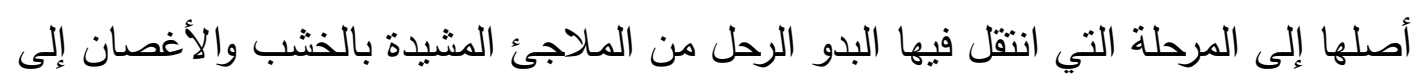
بناء المساكن المستقرة، كذللك وضعوا فرضية عن بداية استخدام الآجر الطيني ، إذ أثناروا

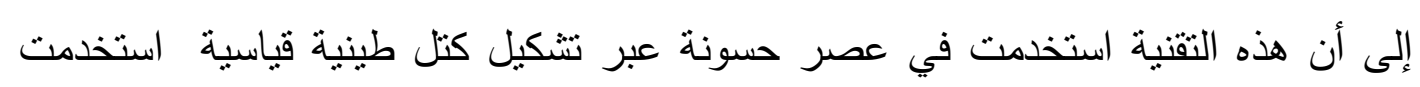

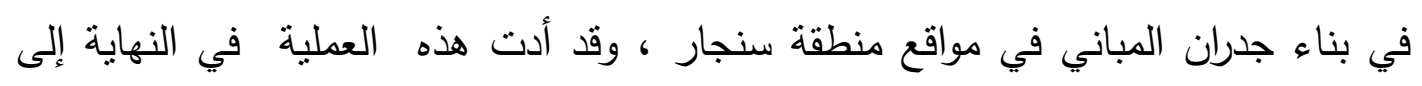
شيوع استخدام الآجر الطيني في عموم بلاد الرافدين.

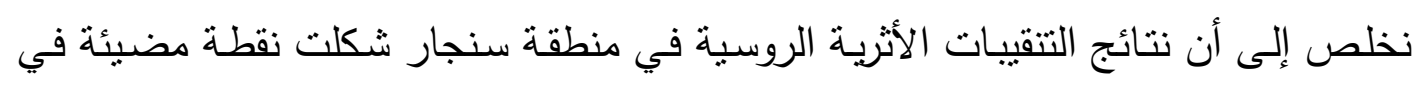

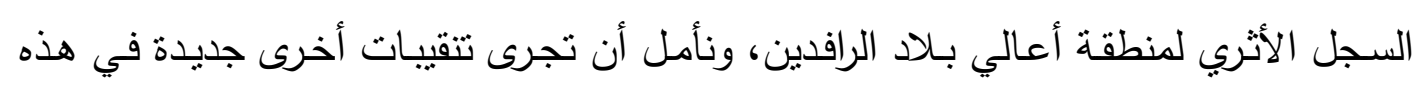

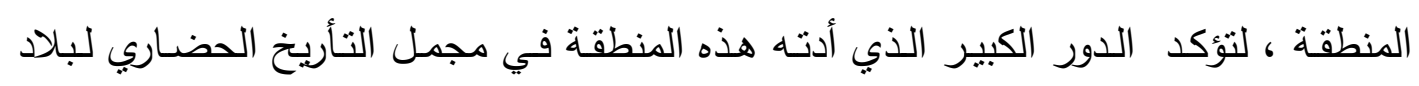
الرافدين. 
أ. أ.د. محمد كامل روكان

التنقيات الروسية في منطقة سنجار شمال العرلق

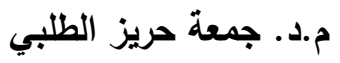

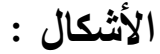
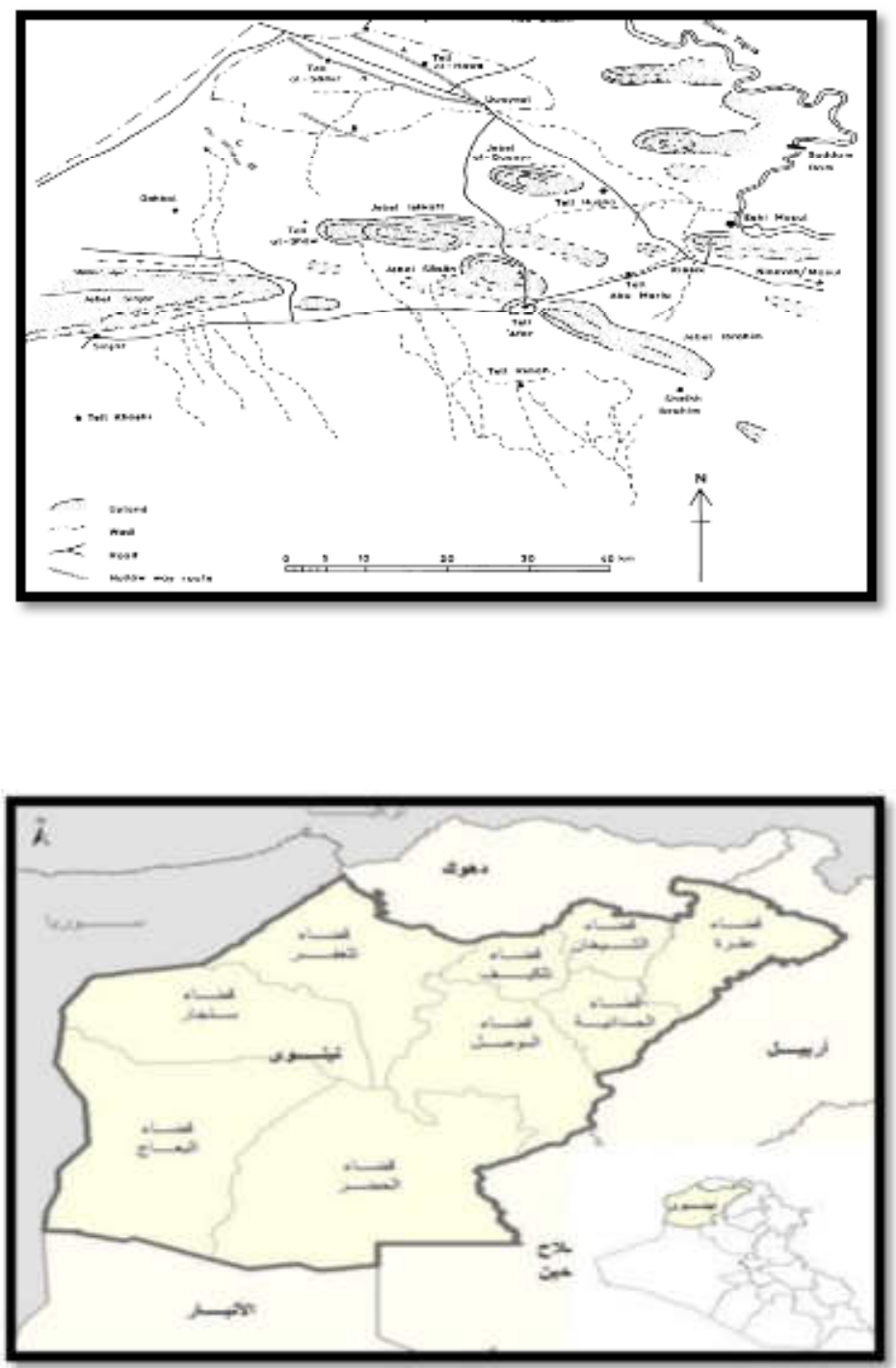

الشكل (1)

خارطة تظهر منطقة سنجار 


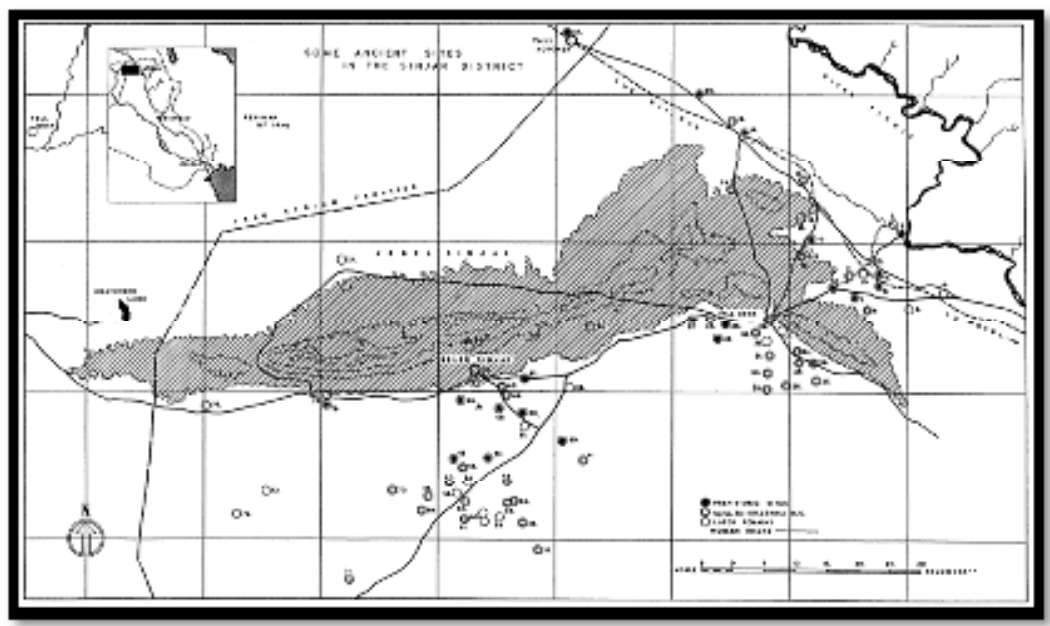

الشكل (r)

بعض المواقع في منطقة سنجار

From : Seton Lloyd،Some Ancient Sites in the Sinjar District .Iraq, Vol. 5 (1938), pp. 123-142

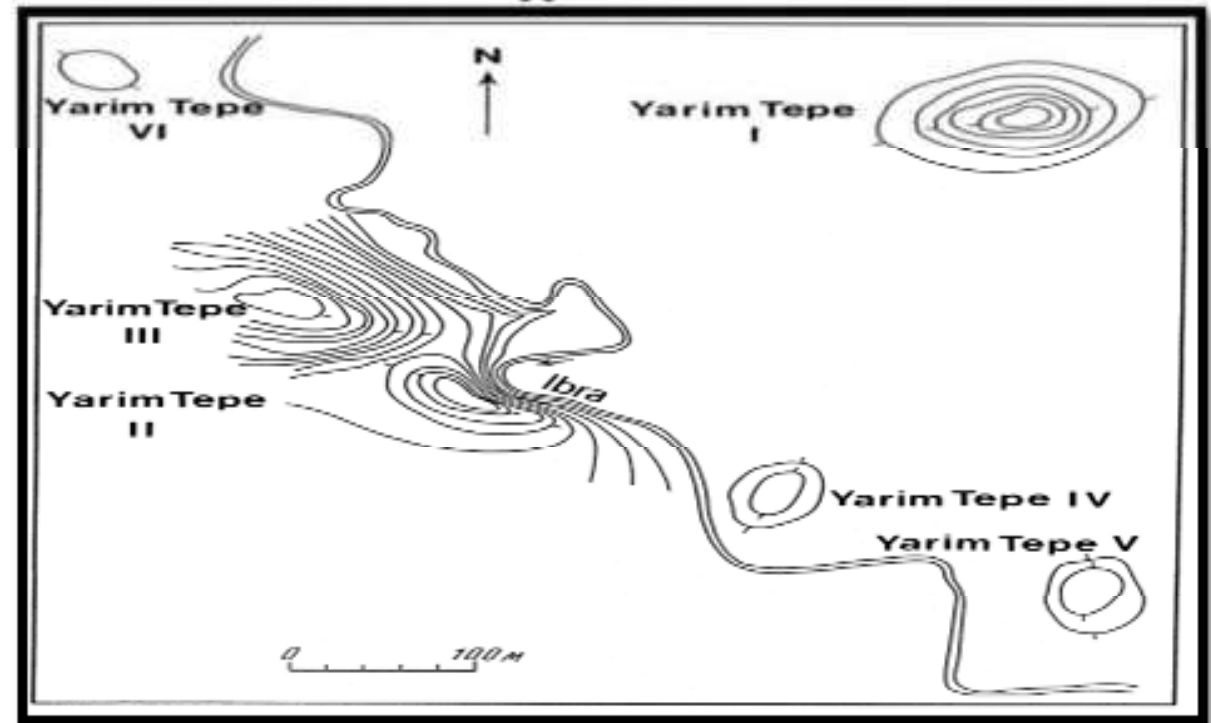

$$
\text { الشكل (r) }
$$

تلول موقع يارم تبة في منطقة سنجار

From: N. Ya. Merpert and R. M. Munchaev : The Earliest Levels at YarimTepe I and YarimTepe II in Northern Iraq.Iraq, Vol. 49 (1987), pp. 1-36 


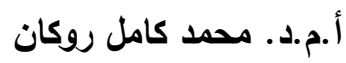

التنقيبات الروسية في منطقة سنجار شمال العرلق

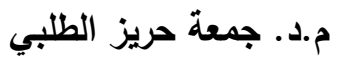

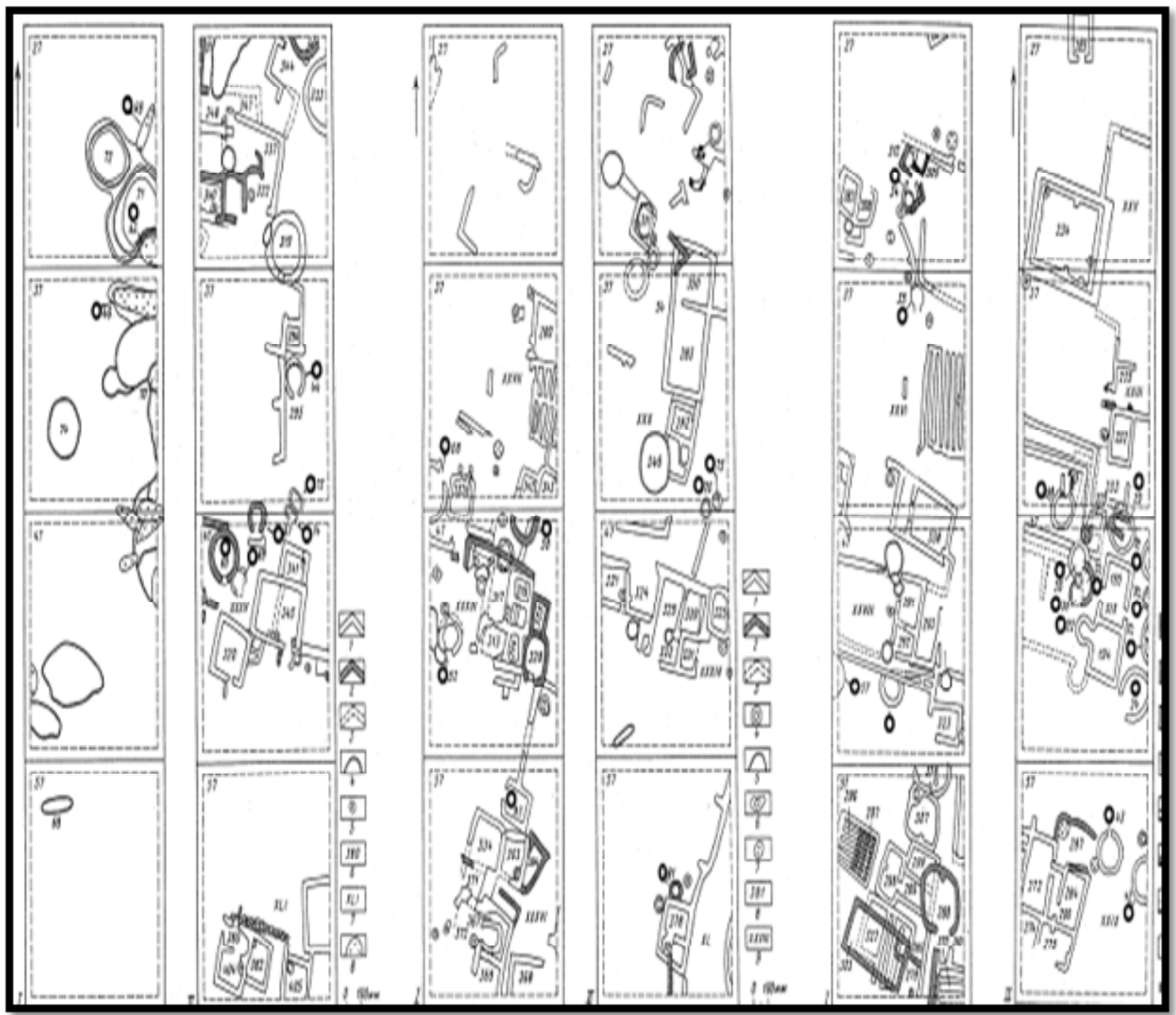

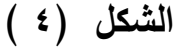

مخطط مباني الطبقات من Y I-9 في موقع يارم تبة ا

From: Merpert, N. Y. The Earliest levels at YarimTepe I and YarimTepe II in Northern Iraq. Iraq. - 1987,Vol. 49. P. 1-36. 


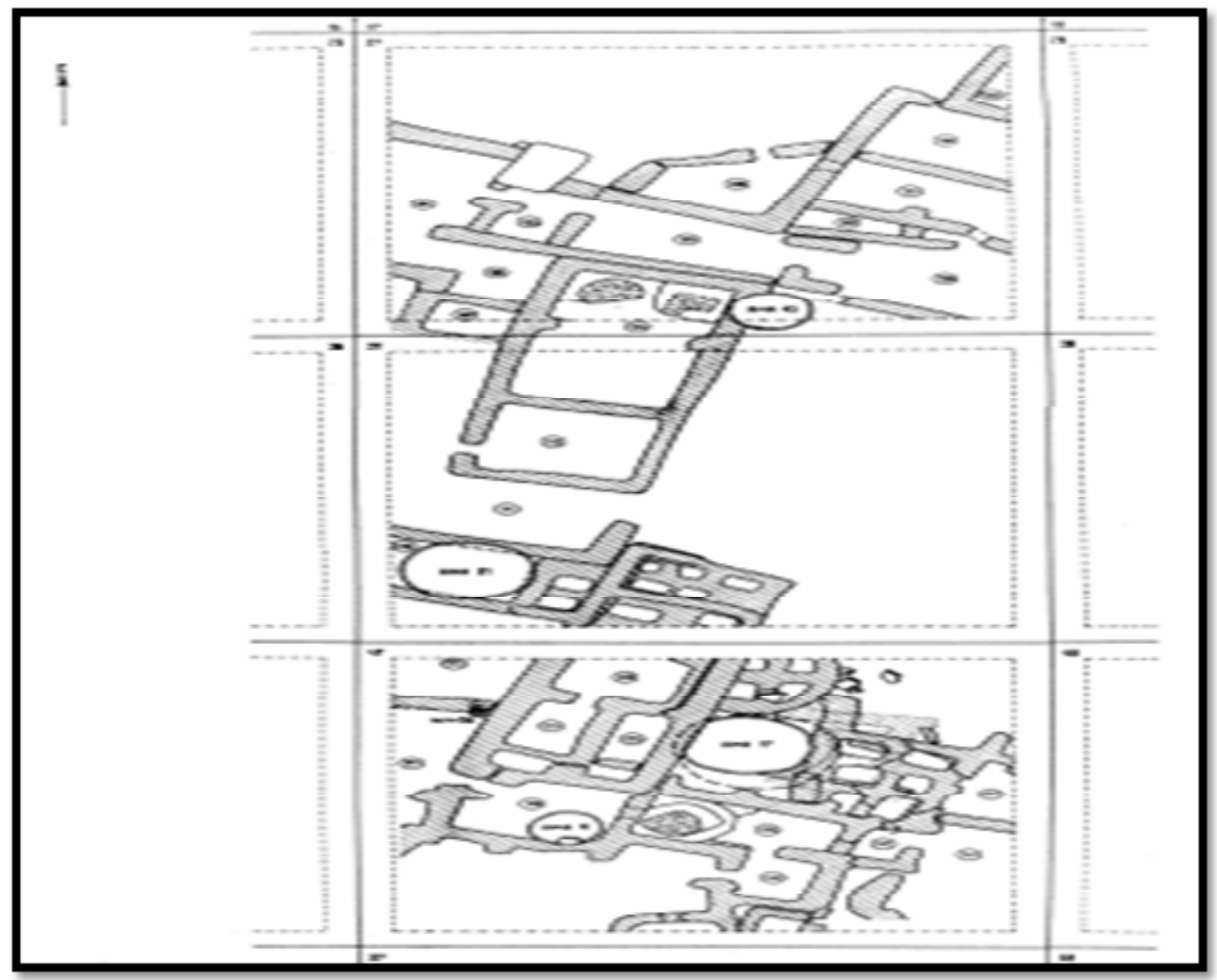

الشكل (0)

مباني الطبقة السادسة في موقع يا م تبة ا

From: Merpert, N. Y. Early agricultural settlements in the Sinjar Plain, Northern Iraq. Iraq. 1973, Vol. 29, № 2.

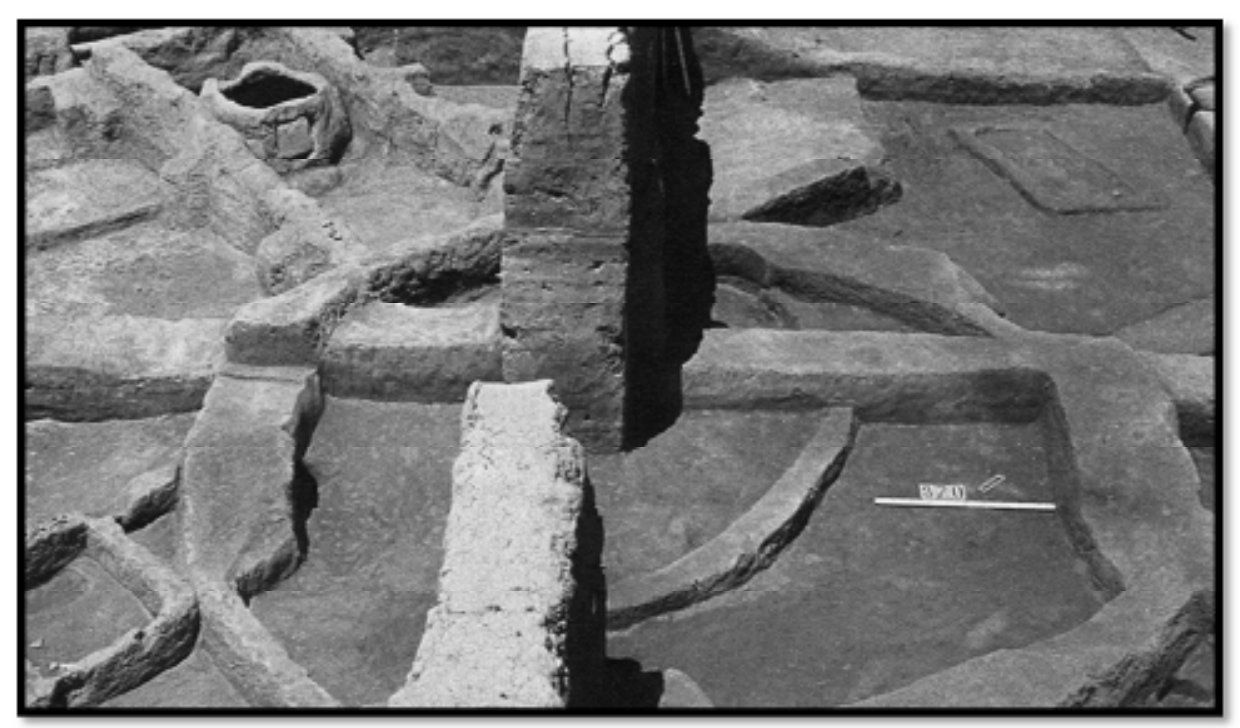

(7) الشكل

مبنى من نوع ثولوي من موقع يارم تبة r 


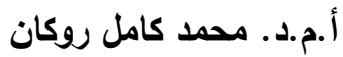

التنقيبات الروسية في منطقة سنجار شمال العرلق

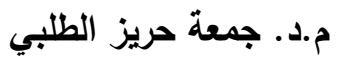

From : Merpert, N. Y.(1977). The investigations of Soviet expeditions in Iraq 1974. Sumer. Vol. 33, № 1. Pl. 7-3, p. 89.

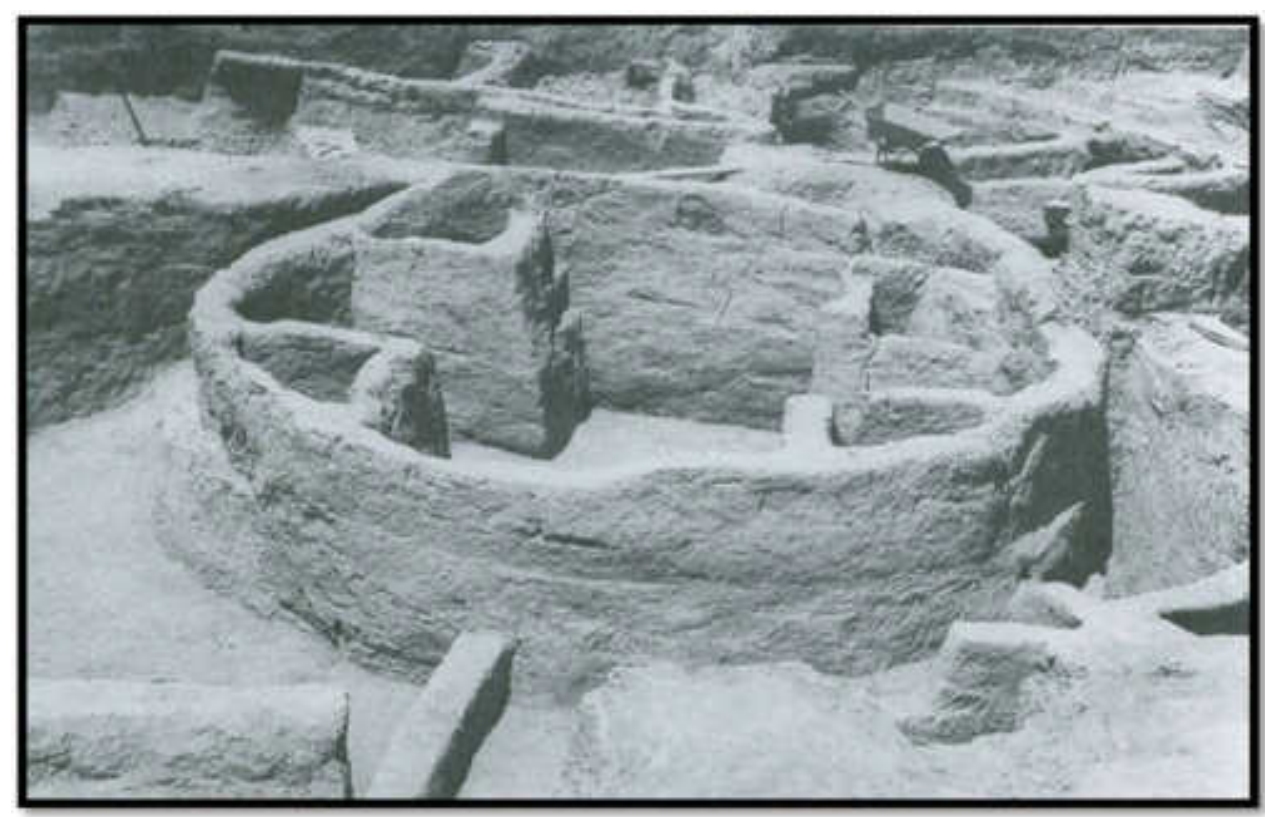

( الشكل ( )

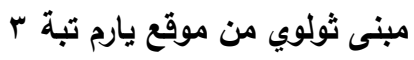

From : Merpert, N. Y. Archaeological studies in the Sinjar valley, 1980. Sumer.1984,Vol. 41, № 2.P. 32-33.

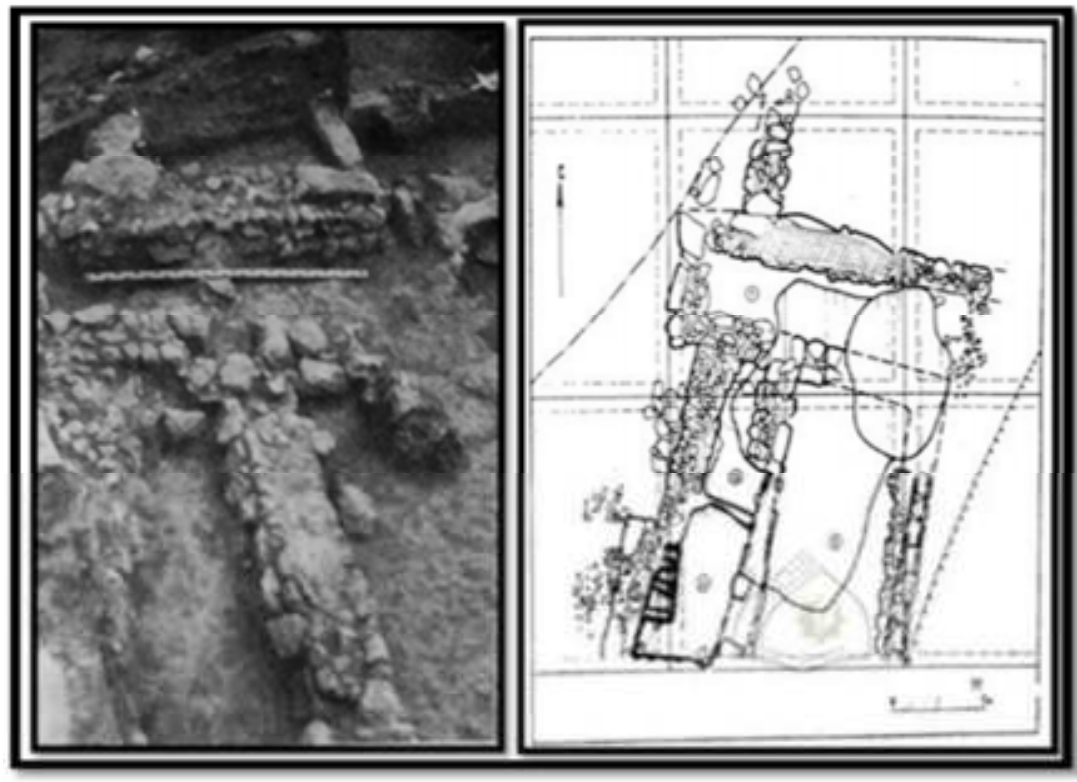

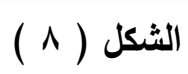

مخطط لبقايا بنائية من موقع المغزلية في منطقة سنجار

From: Merpert, N. Y. Archaeological studies in the Sinjar valley, 1980.Sumer. 1984. - Vol. 41, № 2. fig. 20-29, p. 48-49. 


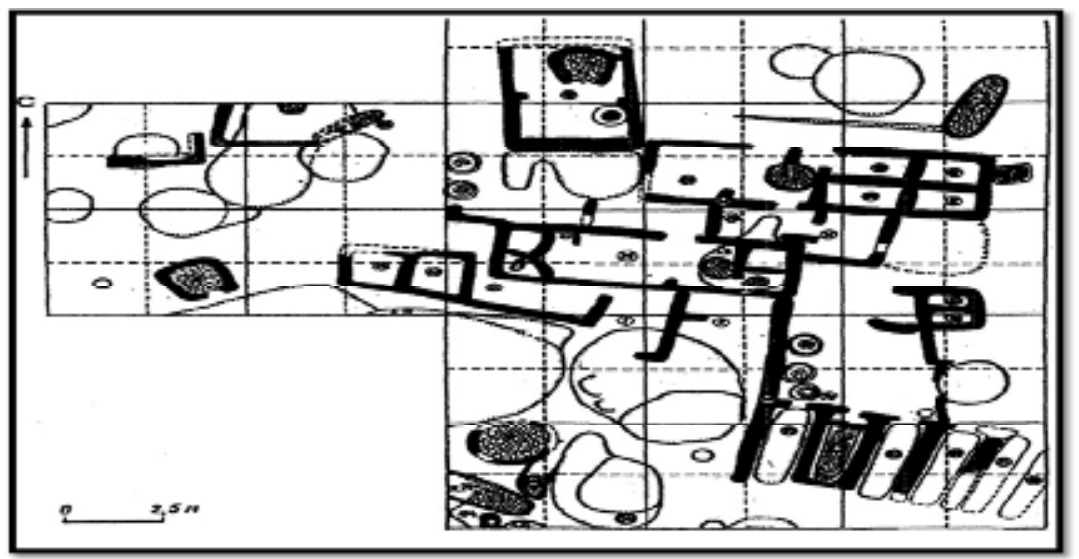

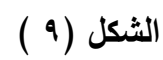

مخطط لبقايا بنائية من موقع سوتو في منطقة سنجار

From: Merpert, N. Y.(1977). The investigations of Soviet expeditions in Iraq 1974. Sumer. Vol. 33, № 1., PI. 27, p. 96.

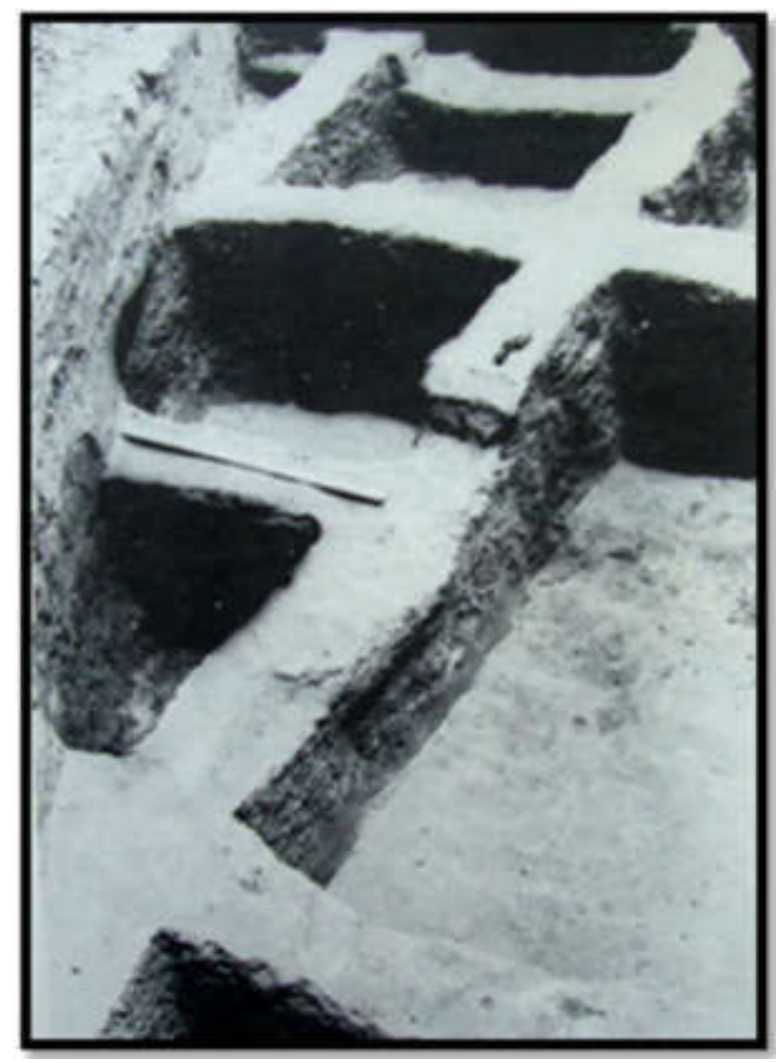

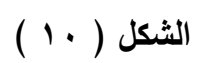

بقايا بنائية من موقع كول تبه

From : Merpert, N. Y. Investigations the Soviet expedition in Northern Iraq 1976.Sumer. -1981. Vol. 37, № 1/2., fig. 19, p. 14. 


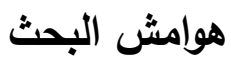

(1) Merpert, N. Y. Archaeological studies in the Sinjar valley, 1980. Sumer.1984,Vol. 41, № 2.P. 32-53.

(2) Merpert, N . Y. The investigation of soviet archaeological expedition in Iraq in the spring 1969 excavations at YarimTepe .Sumer. 1969, Vol. 25.P. 125-131.

(3) Merpert, N. Y. The archaeological research in the Sinjar valley, 1971.Sumer. 1971,Vol. 27, № 1. P. 9-22.

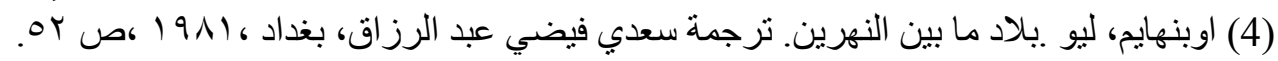

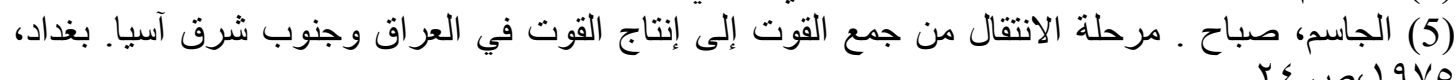

(6) Akkermans, P. An Image of Complexity: The Burnt Village at Late Neolithic SabiAbyad, Syria .Amer. J. of Archaeology.1995, Vol. 99, № 1.- P. 5.

(7) Matthews, R. The archaeology of Mesopotamia, theories and approaches.London;

New York : Routledge, 2003.p.5.

(8) Crawford,H. Sumer and the Sumerians.Oxford,1986,p.6.

(9) Staubwasser, M. Holocene climate and cultural evolution in late prehistoric - early historic West Asia. Quaternary Research.2006, Vol. 66, № 3.P. 372-375.

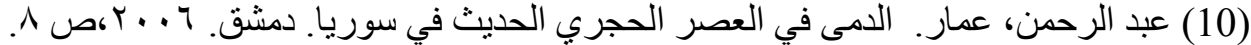

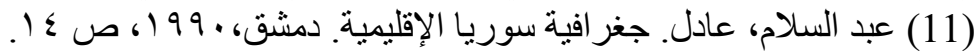

(12) Merpert, N. Y.The Earliest levels at YarimTepeI and YarimTepe II inNorthern Iraq. Iraq. - 1987,Vol.49. P. 1-36.

(13) Nissen, N. J. The Early history of the Ancient Near East 9000-2000 B. C.

Chicago : Univ. of Chicago Press, 1988.p.8-11.

(14) Bakhteger,F,K and Yanashevich, Z.V. Discoveries of Cultivated plants in the early farmingSettlement of YarimTepe 1 and YarimTepe 2 in Northern Iraq. J.

Archaeological Sco,Vol,7,1986,p.167-178.

(15) Lloyd ,Seton. Some Ancient Sites in the Sinjar District.Iraq,Vol,5, 1938,p. 123142.

(16) Merpert, N. Y.1971,Op.Cit,P. 9-22.

(17) Merpert, N. Y. The investigations of Soviet expedition in Iraq 1973. Sumer. 1976,Vol. 32, № 1. P. 25-61.

(18) Merpert, N. Y. The investigations of Soviet expeditions in Iraq 1974

.Sumer.1977,Vol. 33, № 1.P. 68.

(19) Mellaart, J. The Neolithic of the Near East .New York : Scribner's, 1975,p.164.

(20) Merpert, N. Y. 1976, Op.Cit,P. 67.

(21) Merpert, N. Y.19771,Op .Cit ,P. 13.

(22) Merpert, N. Y.1977, Op. Cit, P. 76.

(23) Merpert, N. Y.19771,Op.Cit,10-11.

(24) Merpert, N. Y. 1973,Op.Cit,P. 95-96.

(25) Merpert, N. Y. 1987,Op.Cit,P. 7-8.

(26) Munchaev, R. The Halaf culture: peculiarities of the V Mil. B. C. North Mesopotamian architecture .Al-Rafidan.Vol,18, 1997,P. 71.

(27) Merpert, N. Y. Investigations the Soviet expedition in Northern Iraq 1976. Sumer.1981,Vol. 37, № 1/2.P. 25-26. 
(28) Munchaev, R. M. Excavations at Yarimtepe1972 : forth preliminary rep. Sumer. 1973,Vol. 29, № 1.P. 3-16.

(29) Mellaart, J. The Neolithic of the Near East .New York : Scribner's, 1975,p.159.

(30) Munchaev, R. M. 1973,Op.Cit,P. 12.

(31) Matthews, R. The Early Prehistory of Mesopotamia. 500,000 to 4,500 B. C. Subartu : Studies devoted to upper Mesopotamia (ed). F. Mark.Turnhout,Belgiun,2000. - Vol. 5.p.89-90.

(32) Merpert, N. Y. Archaeological studies in the Sinjar valley, 1980. Sumer.1984,Vol. 41, № 2.P. 32-33.

(33) Merpert, N. Y. Soviet expedition's research at YarimTepe III settlement in North Western Iraq, 1978-1979. Sumer.1984,Vol. 41, № 2. P. 57.

(34) Merpert, N. Y. Soviet expedition surveys in the Sinjar valley. Sumer. -1981, Vol. 37, № 1/2.- P. 55-68.

(35) Merpert, N. Y.1977, OP. Cit,P. 97.

(36) Merpert, N. Y.1976,Op.Cit,P. 25-27 /Mellaart, J. 1975, Op.Cit,p.140.

(37) Matthews, R. The Early Prehistory of Mesopotamia. 500,000 to 4,500 B. C. Subartu : Studies devoted to upper Mesopotamia (ed). F. Mark.Turnhout,Belgiun,2000. - Vol. 5.p.61/Merpert, N. Y. Investigations the Soviet expedition in Northern Iraq 1976. Sumer.1981,Vol. 37, № 1/2.P.37.

(38) Merpert, N. Y.1981,Op.Cit,P. 27-28.

(39) Merpert, N. Y. Early agricultural settlements in the Sinjar Plain, Northern Iraq. Iraq. 1973,Vol. 29, № 2.P. 101 /Merpert, N. Y.1981,Op.Cit,P. 61.

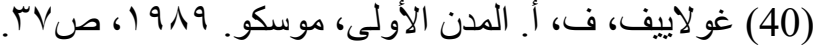

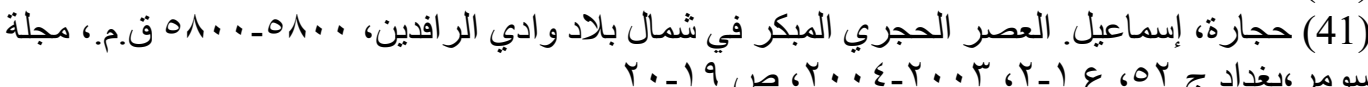

(42) Wilkenson,T.L. The Development of Settlement in the NorthJazera between the 7th and 1st millennia B.C.Iraq,Vol,52,1990,P.49-62.

(43) Akkermans, P. Hunter-gatherer continuity: the transition from the Epipalaeolithic to the Neolithic in Syria. In .From river to the Sea, The Paleolithic and the Neolithic on the Euphrates and in the Northern Levant.ed. O. Aurenche[et al.]. -ledian, 2004.P. 287.

(44) Nissen, N. J. Op.Cit,p.10.

(46) Matthews, R.2000,Op.Cit,p.57.

$$
\text { (45) غولاييف، ف.أ. المصدر السابق الذكر، ص ب؟r. }
$$


7- Akkermans, P. An Image of Complexity: The Burnt Village at Late Neolithic SabiAbyad, Syria . Amer. J. of Archaeology. 1995, Vol. 99, № 1.

8- Akkermans, P. Hunter-gatherer continuity: the transition from the Epipalaeolithic to the Neolithic in Syria. In . From river to the Sea, The Paleolithic and the Neolithic on the Euphrates and in the Northern Levant. ed. O. Aurenche[et al.].ledian, 2004.

9- Bakhteger,F,K and Yanashevich, Z.V. Discoveries of Cultivated plants in the early farmingSettlement of YarimTepe 1 and YarimTepe 2 in Northern Iraq. J. Archaeological Sco,Vol,7,1986.

10- Crawford,H. Sumer and the Sumerians.Oxford,1986.

11- Lloyd ,Seton. Some Ancient Sites in the Sinjar District.Iraq,Vol,5, 1938.

12- Matthews, R. The Early Prehistory of Mesopotamia. 500,000 to 4,500 B. C. Subartu : Studies devoted to upper Mesopotamia (ed). F. Mark.-Turnhout,Belgiun,2000.

13- $\quad$ Matthews, R. The archaeology of Mesopotamia, theories and approaches.London; New York : Routledge, 2003.

14- Mellaart, J. The Neolithic of the Near East .New York : Scribner's, 1975.

15- Merpert, N .Y. The investigation of soviet archaeological expedition in Iraq in the spring 1969 excavations at YarimTepe .Sumer. 1969, Vol. 25.

16- Merpert, N. Y. The archaeological research in the Sinjar valley, 1971.Sumer. 1971, Vol. 27, № 1.

17- Merpert, N. Y. Early agricultural settlements in the Sinjar Plain, Northern Iraq. Iraq. 1973,Vol. 29, № 2.

18- Merpert, N. Y. The investigations of Soviet expedition in Iraq 1973. Sumer. 1976, Vol. 32, № 1.

19- Merpert, N. Y. The investigations of Soviet expeditions in Iraq 1974 .Sumer. 1977, Vol. 33, № 1 .. 
20- Merpert, N. Y. Investigations the Soviet expedition in Northern Iraq 1976. Sumer.1981,Vol. 37, № 1/2.

21- Merpert, N. Y. Archaeological studies in the Sinjar valley, 1980. Sumer.1984,Vol. 41, № 2.

22- Merpert, N. Y. Soviet expedition's research at YarimTepe III settlement in North Western Iraq, 1978-1979. Sumer.1984,Vol. 41, № 2.

23- Merpert, N. Y.The Earliest levels at YarimTepeI and YarimTepe II inNorthern Iraq. Iraq. - 1987,Vol.49.№ 2.

24- Munchaev, R. M. Excavations at Yarimtepe1972 : forth preliminary rep. Sumer. 1973,Vol. 29, № 1.

25- Munchaev, R. The Halaf culture: peculiarities of the V Mil. B. C. North Mesopotamian architecture .Al-Rafidan.Vol,18, 1997.

26- Nissen, N. J. The Early history of the Ancient Near East 9000-2000 B. C. Chicago : Univ. of Chicago Press, 1988.

27- Wilkenson,T.L. The Development of Settlement in the North Jazera between the 7th and 1st millennia B.C.Iraq,Vol,52,1990. 

Contents

\begin{tabular}{|c|c|c|}
\hline$\overline{\text { Page }}$ & Research Name & $\overline{\text { Subject }}$ \\
\hline 1 & Prof. Khalid Salim Ismael & Preface \\
\hline $3-19$ & $\begin{array}{l}\text { Oday Abdulwahhab Al.Noamy } \\
\text { Prof. Khalid Salim Ismael }\end{array}$ & $\begin{array}{l}\text { From Epics of Kings in the Second and } \\
\text { First Millennium B.C. - An Analytical } \\
\text { Study }\end{array}$ \\
\hline $21-44$ & Prof. Dr. Farouk Ismail & The Ransom in Akkadian Texts \\
\hline $45-70$ & $\begin{array}{c}\text { Reem Mohammad Salih } \\
\text { Prof. Dr. Safwan Sami Saeed }\end{array}$ & $\begin{array}{c}\text { Assyrian's Concerns of Fear and Anxiety } \\
\text { Regarding Demons and Evil Spirits }\end{array}$ \\
\hline 71-91 & $\begin{array}{c}\text { Sondos Ali Hammadi } \\
\text { Prof. Dr. Yasser Al-Mashhadani }\end{array}$ & Sivas City before the Seljuk Rule \\
\hline $93-114$ & $\begin{array}{l}\text { Assist. Prof. Dr. Mohammed Kamil Rokan } \\
\text { Dr. Jumaa Heraz Al-Talbe }\end{array}$ & $\begin{array}{c}\text { Russian Excavations in Sinjar Region, } \\
\text { Northern Iraq }\end{array}$ \\
\hline $115-137$ & $\begin{array}{c}\text { Mustafa Ahmed Ali Al-Samarrai } \\
\text { Assist. Prof. Dr. Yasmine Abdul Karim } \\
\text { Mohammed Ali }\end{array}$ & $\begin{array}{c}\text { Residential Houses from the Moncorn } \\
\text { Assyrian Period (911-612) BC. M- } \\
\text { Elected Sites from the Makhul Dam } \\
\text { Project Area }\end{array}$ \\
\hline 139-164 & $\begin{array}{c}\text { Falih Ghdwi Noman Al-Shammary } \\
\text { Assist. Prof. Dr. Haider Farhan Hussein } \\
\text { Al-Subaihawi }\end{array}$ & Heritage Mosques in Sinjar City \\
\hline $165-185$ & Assist Prof. Dr.Hussein .Y.Hazim & $\begin{array}{l}\text { Carbonated Grains and it's Role in } \\
\text { Archaeological Detection during } \\
\text { Prehistory - An Analytical Study }\end{array}$ \\
\hline $187-211$ & $\begin{array}{l}\text { Ashraf Aziz Abdul - Karim Al_Halay bik } \\
\text { Dr. Shakeeb Rashid Bashir Al- Fattah }\end{array}$ & $\begin{array}{c}\text { The Efforts of Scientific Families in } \\
\text { Building Schools and Teaching (Ibn Al- } \\
\text { Jawzi Family as a Model) }\end{array}$ \\
\hline 213-233 & $\begin{array}{l}\text { Asst. prof. Dr. Wasnaa Hasoun Younis } \\
\text { al-Aghaa }\end{array}$ & $\begin{array}{l}\text { Motives behind the Mummification of } \\
\text { Animals by the Ancient Egyptians }\end{array}$ \\
\hline $235-261$ & Dr. Aram J. Hassan Hamawand & $\begin{array}{l}\text { The Brick Completion Receipts from the } \\
\text { City of Pekasi, "Till Abu-Antik" } \\
\text { "An Analytical Study of Unpublished } \\
\text { Cuneiform Texts" }\end{array}$ \\
\hline 263-279 & $\begin{array}{l}\text { Dr. Mohanad Khalaf Jamen Al shamari } \\
\text { Hanan Abdul-Hamzah Beuawe }\end{array}$ & $\begin{array}{l}\text { Unpublished Economic Texts from Ur III } \\
\text { Dynasty }\end{array}$ \\
\hline $281-302$ & $\begin{array}{c}\text { Muthanna Saadoun Dhafer Al-Hindawi } \\
\text { Dr. Mahmoud Ibrahim Hussien } \\
\text { Dr. Dalia Mohamed El-Sayed } \\
\end{array}$ & $\begin{array}{l}\text { Demons and Evil Spirits in Ancient Iraq } \\
\text { in Light of Cuneiform Texts }\end{array}$ \\
\hline
\end{tabular}


12- The original research papers submitted to the magazine are not returned to their owners, whether published or not.

13- Tables and figures are numbered in a row according to their appearance in the research, provided with titles, submitted with separate papers, blueprints are submitted in black ink and images to be in high resolution.

14- The marginal numbers are written in parentheses and are presented in series at the end of the research.

15- The full source name is indicated in the margin, with the abbreviated source in parentheses at the end of the margin.

16- The researcher is responsible for correcting the linguistic and typographical errors in his research.

17- The magazine operates according to self-funding. Therefore, the researcher bears the publication fees of $(100,000)$ one hundred thousand Iraqi dinars.

18- Each researcher shall be provided with one copy of his research. As for the full copy of the journal, it is requested from the magazine's secretariat and a price is determined by the Editorial Board.

19- The papers should be sent to the journal e-mail: 


\section{Publishing rules in Athar Al-Rafedain Journal (AARJ):}

1- The journal accepts scientific research that falls in specializations:

- Ancient Archaeology and Islamic Archaeology .

- Ancient languages with their dialects and comparative studies.

- Cuneiform Inscriptions and ancient lines.

- Historical and cultural studies

- Archaeological geology.

- Archaeological survey techniques.

- Anthropological studies.

- Conservation and restoration.

2- Research papers shall be submitted to the magazine in both Arabic and English.

3- The research shall be printed on (A4) paper, word-2010 system, with double spaces between lines, Simplified Arabic font for Arabic language, Times New Roman for English language, delivered on $\mathrm{CD}$, and in two paper based copies.

4- The title of the research should be printed in the middle of the page, followed by the name of the researcher, his academic degree, his full work address, and e-mail.

5- The research should contain an abstract in Arabic and English languages, it shouldn't exceed (100) words.

6- The abstract of the research in English contains the title of the research, the name of the researcher, his academic degree, his full workplace, and his e-mail.

7- The research must include keywords related to the title of the research and its content.

8- That the research was not previously published or was submitted to obtain a degree or is derived from the intellectual property of another researcher, and the researcher must undertake this in writing when submitting it for publication.

9- The researcher is obliged to follow the correct scientific foundations in his research.

10- The researcher is obligated to amend his research terms to suit the experts 'suggestions and the method of publishing in the journal.

11- The number of research pages does not exceed (25) pages, and in case of exceeding the required number, the researcher shall pay an additional amount for each additional page. 


\author{
Arabic Language Expert \\ Dr. Maan Yahya Mohammed \\ Dep. Of Arabic Language /College of Arts / University of Mosul
}

\author{
English Language Expert \\ Assist. Lect. Ammar Ahmed Mahmood \\ Dep. Of Translation Language / College of Arts / University of Mosul
}

Design Cover

Dr. Amer Al-Jumaili 


\title{
$\underline{\text { Editorial Board }}$
}

\author{
Prof. Khalid Salim Ismael \\ Editor-in-Chief
}

\section{Assist Prof. Hassanein Haydar Abdlwahed \\ Managing Editor}

\section{Members}

Prof. Elizabeth Stone

Prof. Adeileid Otto

Prof. Walther Sallaberger

Prof. Nicolo Marchetti

Prof. Hudeeb Hayawi Abdulkareem

Prof. Jawad Matar Almosawi

Prof. Rafah Jasim Hammadi

Prof. Abel Hashim Ali

Assist Prof. Yasamin Abdulkareem Mohammed Ali

Assist Prof. Vyan Muafak Rasheed

Assist Prof. Hani Abdulghani Abdullah 



\section{Journal}

\section{Athar Al-Rafedain}

Accredited Scientific Journal

It Search's in Archaeology of Iraq and Ancient Near East

Published by College of Archaeology - University of Mosul

E-Mail: uom.atharalrafedain@gmail.com

Vol.6 / No.1

Rejab. 1442 A.H. / Feb. 2021 A.D. 

